\title{
Determining kinetic energy distribution of the working medium in a centrifugal disc finishing process-part 2: experimental analysis with the use of acoustic emission signal
}

\author{
Paweł Sutowski $^{1}$ (D) Jarosław Plichta ${ }^{1} \cdot$ Paweł Kałduński $^{1}$ \\ Received: 21 May 2019 / Accepted: 23 May 2019 / Published online: 7 June 2019 \\ (C) The Author(s) 2019
}

\begin{abstract}
This paper addresses the problem of estimating the kinetic energy distribution of the working medium in a centrifugal disc finishing process. Centrifugal disc finishing is a highly effective way of finishing surfaces, especially in the case of complex shapes, made from a variety of materials. The process is, however, frequently very time-consuming. The identification method of a region with a high kinetic energy potential by measurement of acoustic emission signal is described and verified by surface roughness tests. Signal analysis was carried out in both time and frequency domain. The results presented in experimental tests and analyses indicate that various parameters of the AE signal, including its energy, are variable and determined by abrasive particles' velocity and location in an axial cross section of the working medium. On the basis of the root mean square value of the signal, the maps of the distribution of the energy potential of the working medium are presented. Experimental results demonstrate process improvement and a significant reduction (approx 60\%) of the arithmetic mean deviation of surface roughness, obtained at the same time of machining. The article also presents the functional relations between the selected AE signal descriptors and the rotational speed of the working chamber rotor. Since the article is a continuation of the previous studies, the results obtained were briefly referred to the simulation results.
\end{abstract}

Keywords Disc finishing machining $\cdot$ Kinetic energy $\cdot$ Working medium $\cdot$ Efficiency $\cdot$ Acoustic emission

\section{Acronyms}

AE Acoustic emission

AHV Area of high values

DEM Discrete element method

IACS Unit, values are given in reference to the

International Annealed Copper Standard

MFCC Mel-frequency cepstral coefficients

RMS Root mean square (value)

ROI Region of interest

SPL Sound pressure level (acoustic pressure)

Paweł Sutowski

pawel.sutowski@tu.koszalin.pl

Jarosław Plichta

jaroslaw.plichta@tu.koszalin.pl

Paweł Kałduński

pawel.kaldunski@tu.koszalin.pl

1 Department of Mechanical Engineering, Koszalin University of Technology, 15-17 Racławicka St., 75-620 Koszalin, Poland

\begin{tabular}{|c|c|}
\hline $\begin{array}{l}\text { STE } \\
\text { ZCR }\end{array}$ & $\begin{array}{l}\text { Short-time energy } \\
\text { Zero-crossing rate }\end{array}$ \\
\hline \multicolumn{2}{|c|}{ Latin symbols } \\
\hline$A_{\mathrm{HV}}$ & $\begin{array}{l}\text { Measured area of high values of the signal } \\
\text { measured in ROI }\left(\mathrm{mm}^{2}\right)\end{array}$ \\
\hline$A_{\text {sensor }}$ & Sensor contact area $\left(\mathrm{mm}^{2}\right)$ \\
\hline$A E_{\text {raw }}$ & Raw (pre-filtered) acoustic emission signal (V) \\
\hline$A E_{\mathrm{rms}}$ & $\begin{array}{l}\text { Root mean square value of acoustic emission } \\
\text { signal }(\mathrm{V})\end{array}$ \\
\hline$C$ & Value of spectral centroid for signal \\
\hline$C_{0}$ & Capacitance $(\mathrm{F})$ \\
\hline$D_{f}$ & Electric displacement field $\left(\mathrm{C} \cdot \mathrm{m}^{-2}\right)$ \\
\hline$E_{f}$ & Electric field $\left(\mathrm{N} \cdot \mathrm{C}^{-1}\right)$ \\
\hline$E_{S}$ & Energy of signal $(\mathrm{mJ}=\mathrm{W} \cdot \mathrm{ms})$ \\
\hline$E_{\mathrm{STE}}$ & Short-time energy of a discrete-time signal $\left(\mathrm{V}^{2}\right)$ \\
\hline$E_{\text {Total }}$ & $\begin{array}{l}\text { Total kinetic energy }(\mathrm{J}=\mathrm{W}, \mathrm{s}=\mathrm{V} \cdot \mathrm{A} \cdot \mathrm{s} \\
\text { or } \mathrm{mJ}=\mathrm{W} \cdot \mathrm{ms})\end{array}$ \\
\hline$f_{s}$ & Sampling frequency $(\mathrm{MHz})$ \\
\hline$F$ value & Value of the Fisher-Snedecor statistical test \\
\hline$h_{p}$ & Piezoelectric constant \\
\hline & Value of spectral entropy for signal, \\
\hline
\end{tabular}




\begin{tabular}{|c|c|}
\hline$i$ & Current (A) \\
\hline$i_{c}$ & Single contact number (index) \\
\hline$i_{\mathrm{fr}}$ & Number (index) of the signal frame \\
\hline$I_{\mathrm{rms}}$ & Effective value of current (A) \\
\hline$m_{\text {avg }}$ & Average media mass (g or kg) \\
\hline$n$ & $\begin{array}{l}\text { Rotational speed (machine working speed) } \\
(\mathrm{rpm}(\mathrm{rev} / \mathrm{min}))\end{array}$ \\
\hline$n_{\mathrm{sq}}$ & The sequence of signal samples \\
\hline$N_{c}$ & Total number contacts \\
\hline$P_{\text {avg }}$ & The average signal power value $(\mathrm{W}=\mathrm{V} \cdot \mathrm{A})$ \\
\hline$P_{s}$ & Signal power value $(\mathrm{W}=\mathrm{V} \cdot \mathrm{A})$ \\
\hline$R$ & Measuring system resistance $(\Omega)$ \\
\hline $\mathbf{R}$-square & $\begin{array}{l}\text { Value of the adjusted coefficient } \\
\text { of determination }\end{array}$ \\
\hline$R a$ & $\begin{array}{l}\text { Arithmetic mean deviation of the surface } \\
\text { profile }(\mu \mathrm{m})\end{array}$ \\
\hline$s_{f}$ & Complex frequency \\
\hline$S$ & $\begin{array}{l}\text { Sound pressure level of signal to the } \\
\text { reference level }(\mathrm{dB})\end{array}$ \\
\hline$S a$ & $\begin{array}{l}\text { Arithmetic mean deviation of surface } \\
\text { roughness }(\mu \mathrm{m})\end{array}$ \\
\hline$t$ & time $(\mathrm{s})$ \\
\hline$t$ value & Student's $t$ test value \\
\hline$T$ & Period of time (duration) (s) \\
\hline$u$ & voltage $(\mathrm{V})$ \\
\hline$U_{\mathrm{rms}}$ & The effective value of the signal voltage (V) \\
\hline$v$ & Linear velocity $(\mathrm{mm} / \mathrm{s})$ \\
\hline$W_{L}$ & Length of the signal frame (samples) \\
\hline$x$ & Discrete signal sample $(\mathrm{V})$ \\
\hline$Z_{\mathrm{CR}}$ & Zero-crossing rate \\
\hline \multicolumn{2}{|c|}{ Greek symbols } \\
\hline \multicolumn{2}{|c|}{$\alpha \quad$ Level of statistical significance } \\
\hline \multicolumn{2}{|c|}{$\varepsilon \quad$ Permittivity $\left(\mathrm{F} \cdot \mathrm{m}^{-1}\right)$} \\
\hline \multicolumn{2}{|c|}{$\zeta \quad$ Deflection (displacement) $(\mathrm{mm})$} \\
\hline \multicolumn{2}{|c|}{$\lambda$ Length of wave (mm) } \\
\hline
\end{tabular}

\section{Introduction}

This article is a continuation of the research, this time in an experimental form, on the problem of determining the kinetic energy distribution in the working medium during a centrifugal disc finishing process. A companion paper [1] describes the problem, a theoretical analysis, and results of numerical simulation research aimed at an identification of the variability of velocity and energy of the working medium. The numerical simulation tests, carried out with the use of the discrete element method (DEM), indicated that there are regions with different values of velocity and levels of kinetic energy in the working medium. This provides the basis for determining the distribution of kinetic energy in the actual finishing process. This information can be used to increase machining intensity and efficiency and to reduce machining time by positioning the workpiece in a selected region with a measured high machining potential.

In the centrifugal disc finishing process, the abrasive media freely participate in the finishing and, therefore, the process itself consists of their free dislocation in relation to the surface machined. As a result of this motion, the abrasive particles interact randomly with the workpieces. The phenomena that occur upon contact between bodies moving in relation to one another, in particular the energy conservation principle, are used for machining the surface of workpieces. The purpose of a fixturing method is to hold the part in a high interaction region with the media. In the case of a fixed part, the part edges and surfaces interact with loose media with a higher force than that developed in conventional mass finishing processes, in which the part is placed randomly in the machine chamber. Fixture arrangements also promote quicker working cycle times.

The state of the art in respect to estimation determining the kinetic energy distribution in the working medium by numerical method (DEM) has been reviewed in the companion paper [1], so attention is centered here on experimental verification of previous results.

The centrifugal disc finishing process is a relatively new mass finishing technique [2], which has been developing rapidly since the 1990s. The Web of Science database reports only 14 articles directly related to the analysis of the centrifugal disc finishing process (in the science technology domain). In this case, Google Scholar reports 38 papers in response to a query concerning "centrifugal disc finishing" or "finishing by centrifugal disc," starting from US patents for a centrifugal disc finishing apparatus, by modeling process, up to an improvement of performance research.

The analysis of the state of knowledge in the field of experimental research and evaluation of kinetic energy of the working medium has shown that two basic methods are used in this field, in which Almen measuring systems or force component measurement sensor are used, but both methods focus on a vibratory finisher.

The Almen test (developed and patented by John O. Almen in 1942, [3]) is used to measure the kinetic energy of abrasive grains - machining intensity. It measures the amount of deflection (curvature) of standardized control samples in the form of metal strips (made of spring steel), which have been subjected to the action of the assumed medium.

When using the Almen system (Fig. 1a), the intensity of impact action of abrasive media in centrifugal disc finishing machines is determined by the curvature of the Almen strip, which is deformed as a result of its one-sided deformations. Standardized strips made of soft material and used for measurement are placed in a special fixture with one face covered and the other face exposed to interactions with abrasive media (Fig. 1b).

As a result of one-sided deformation, the impacted surface of the measuring strip is elongated, which causes its deflection and a curve or concavo-convex contour due to the difference in 
a)

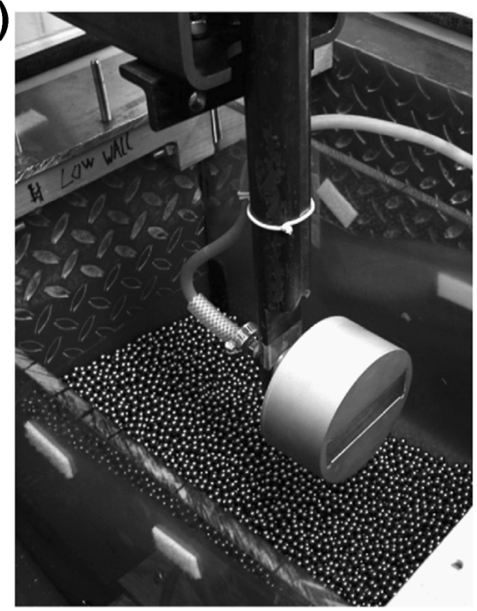

b)

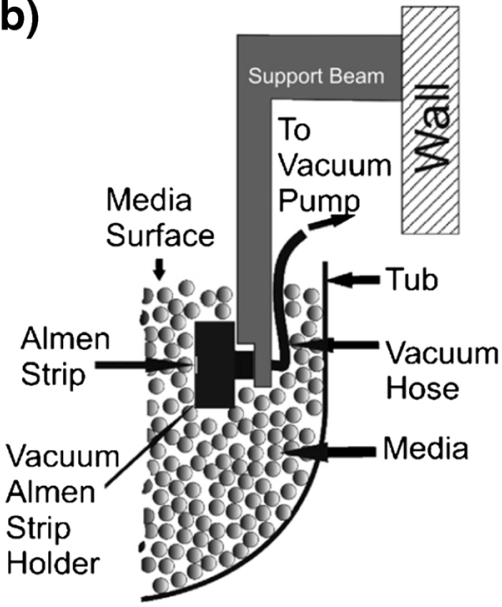

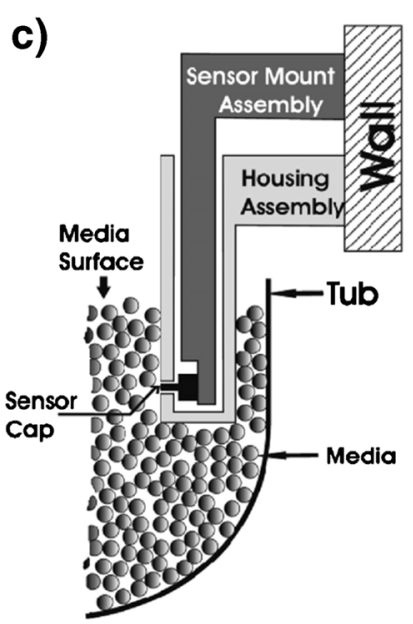

Fig. 1 Almen system. a Experimental setup. b Schematic of Almen strip vacuum fixture immersed in tub finisher. c Force sensor and housing schematic $[4,5]$. $\mathbf{b}$ and $\mathbf{c}$ are not to scale

compressive stress in opposite faces. The measurement of the radius of the strip curvature (Fig. 2b) can be used to obtain an indication of the effectiveness of the machining operation and a measurement of the state of stresses and the impact force of abrasive media.

For measuring the deflection of metal test strips, the Almen gauge is a precision device used (Fig. 2a). The gauge is fitted with a high accuracy digital indicator that is capable of measuring the stress-induced curvature termed as "arc height" of the metal strip. A disadvantage of this method is the deflection limit. Experiments have shown that the "arc" value increases exponentially as a function of machining time [5], which means that over time, the sensitivity of this method decreases.

The method of measurement with the Almen strip makes it possible to determine the energy level of the stream of the abrasive medium, theoretically, in different locations. It can be also classified as a direct measurement. The disadvantage of this method is a relatively large size of the measuring plate (75 mm), which makes the measurement results averaged, with a high value of deviation, from a relatively large contact area. Until now, this method has been used for determining the energy of the working medium, only in relation to the vibratory type of surface barrel finishing, but indirectly, if we consider detailed solutions and methodology.

Ciampini et al. used the Almen system in vibratory finishing to quantify the effect of varying process parameters on the aggressiveness of the process. More aggressive finishing conditions, characterized by greater impact velocities, caused more plastic deformation and resulted in more Almen strip deflection in shorter finishing time. The total kinetic energy was calculated on the basis of the value of effective impact velocity (recalculated from maximum impact force recorded by the sensor) [4]:

$E_{\text {Total }}=\frac{m_{\mathrm{avg}} \sum_{i_{c}=1}^{N_{c}} v_{i_{c}}^{2}}{2 T A_{\text {sensor }}}$,

where $m_{\text {avg }}$ is the average media mass, $v$ is the effective impact velocity, Tis the duration of force signal, $A_{\underline{\underline{\text { sensor }}}}$ is the force sensor
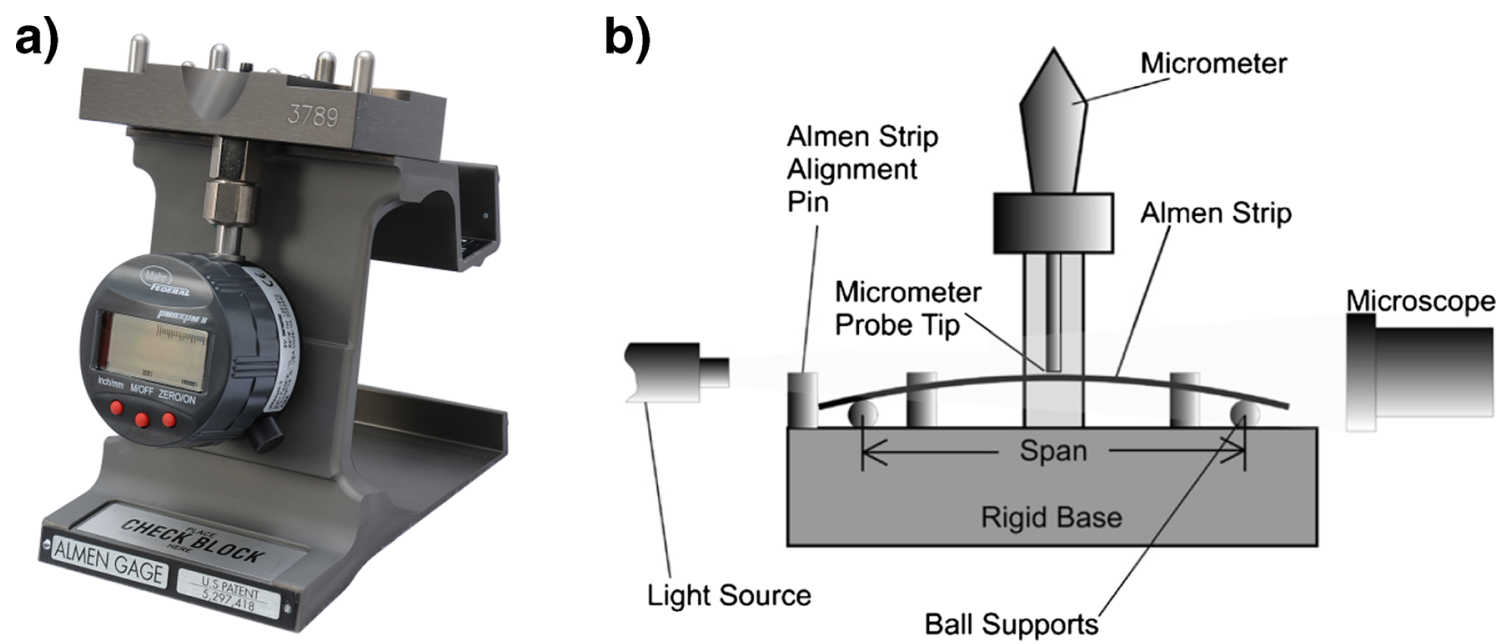

Fig. 2 Almen gauge measuring setup. a Gauge device. b The variant of arc height gauge developed using a microscope [5] 
Fig. 3 Typical force signal recorded over $5 \mathrm{~s}$ when the sensor is submerged in the vibratory finisher [4]

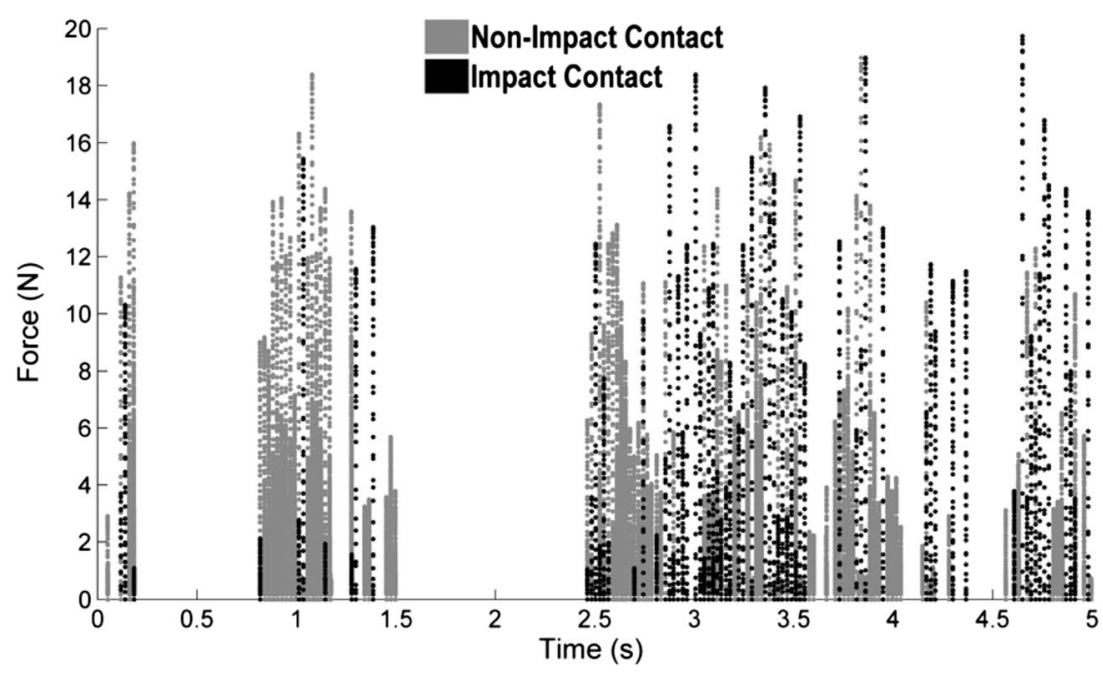

contact area, $N_{c}$ is the total number of contacts during $T$, and $i_{c}$ is the single contact number (index).

The results presented in [4] show that during more than $85 \%$ of the finishing time, the sensor did not register a contact of any type (impact or non-impact) (Fig. 3). The authors are surprised; this is a significantly larger fraction than the $50 \%$ that might be expected as a result of media movement towards and away from the sensor.

The "non-impact contacts" were characterized by much longer contact duration $(0.8 \mathrm{~ms})$, in opposition to "impact contacts" with short contact duration $(0.05 \mathrm{~ms})$. Non-impact contacts are believed to be due to a single piece of media being pressed into the sensor by the surrounding media.
It can be assumed that the problem of much less frequent contact detection as compared with the author's analysis may be caused by low sensitivity of the force sensor to low-energy interactions (e.g., rolling, friction).

On the basis of the results of the previous research on abrasive processes, the authors decided to determine the energy of the working medium by measuring the acoustic emission (AE) signal, which is often considered to be a much more effective measuring tool, in comparison with force measurement.

In general, acoustic emission is known as stress-wave emission and is a common tool used to monitor events occurring during various processes, including abrasive and erosion
Fig. 4 Possible sources of acoustic emission impulses in the centrifugal disc finishing process - the interaction of single pieces of medium with the machined surface is schematically presented in this drawing

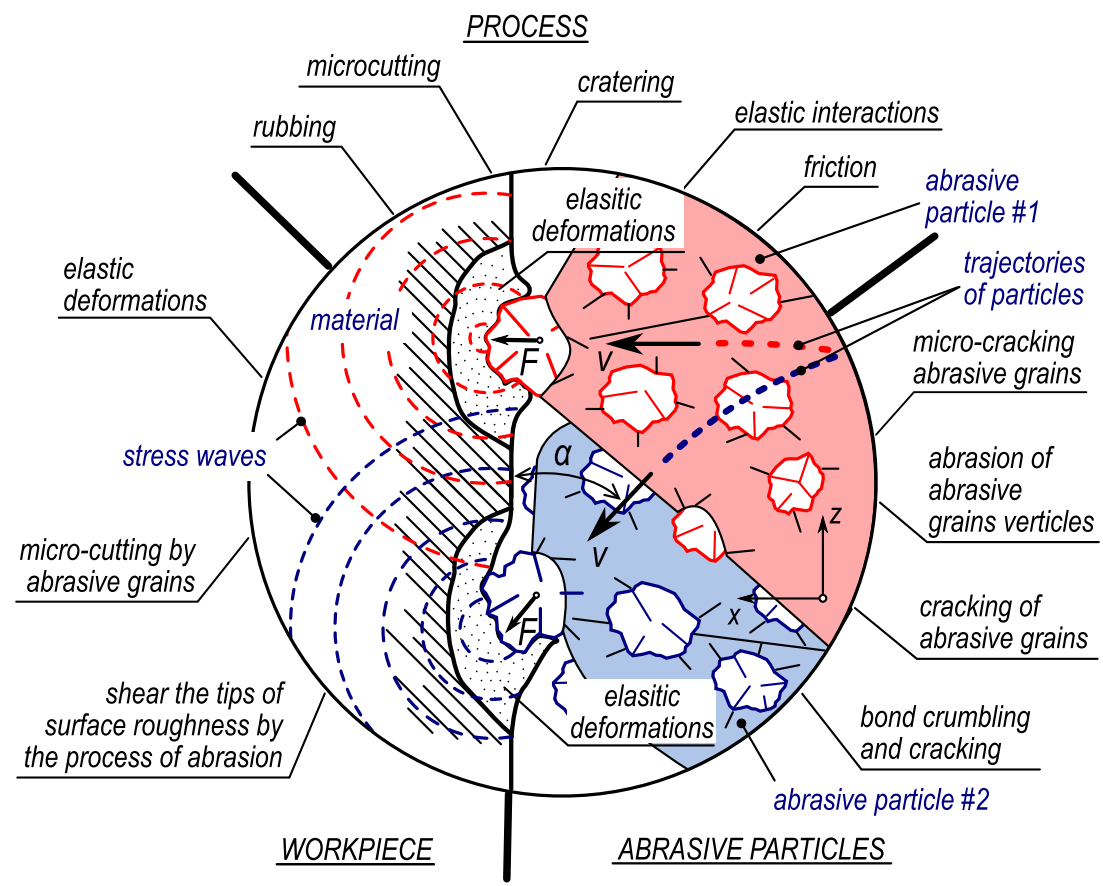


Fig. 5 Experimental setup. a General view of EC6-WET machine. b Interior view of the working chamber. c System for adjusting the position of the workpiece inside the machine chamber

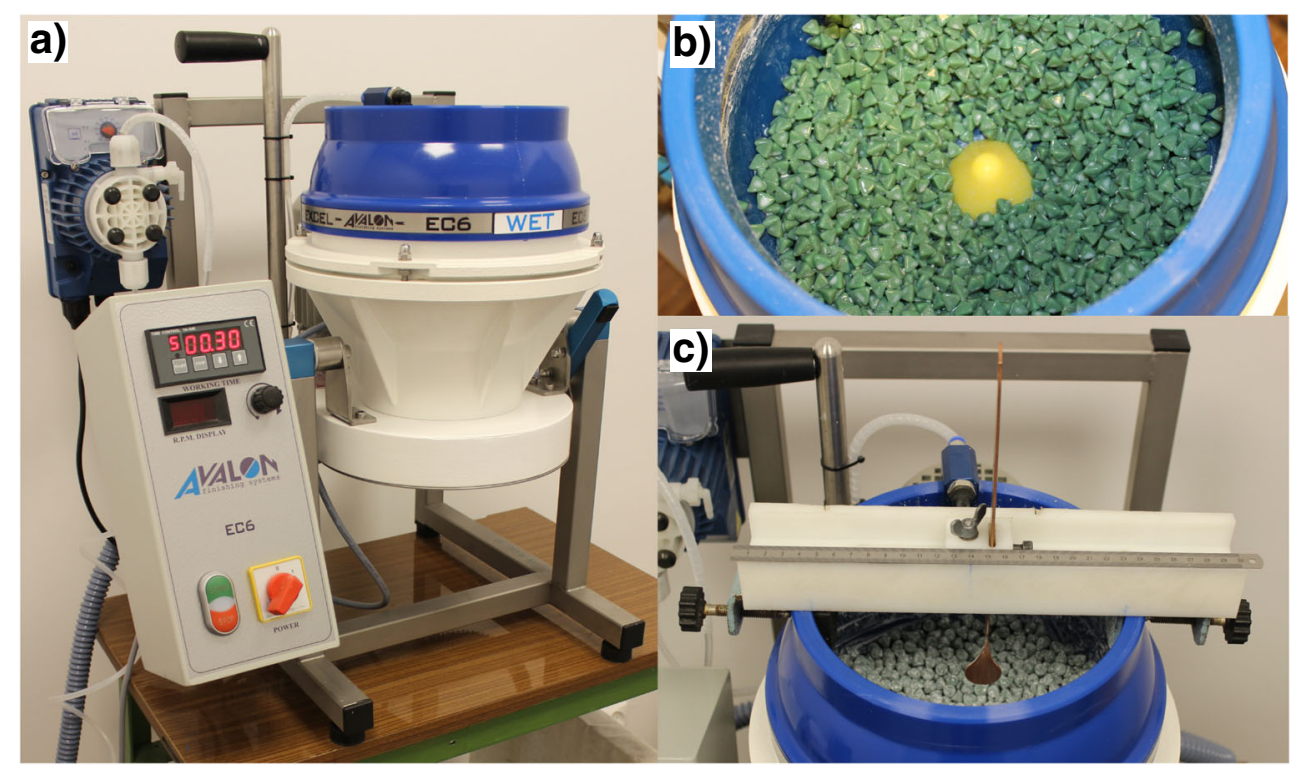

processes. So far, the use of this type of sensor in centrifugal disc finishing process research has not been noticed by authors. Sutowski and Sutowska [6] presented a possible AE diagnostic method to be applied in the abrasive waterjet machining, cylindrical grinding [7], abrasive electro-discharge grinding process [8], and analysis of decohesion process of abrasive grains [9].

Acoustic emission, as the phenomenon of radiation of surface elastic waves (Rayleigh waves), occurs when a material undergoes irreversible changes in its internal structure, for example, as a result of crack formation or plastic deformation. In the case of the centrifugal disc finishing process, the phenomena occurring in the machining zone and evoking the formation of stress waves can be defined by a minimum of three forms (Fig. 4):

- Cutting off the vertices of the unevenness of the workpiece surface as a result of mechanical interactions with media irregularities

- Microcutting due to the penetration workpiece material by active grains of a single piece of media

- Smoothing or rubbing (cratering) the surface of the workpiece by plastic deformations

The research and results presented below were based on the above assumptions and on the fact that $\mathrm{AE}$ can be related to an irreversible release of energy.

\section{Experimental setup and procedure}

In the tests conducted, the distribution of energy in the working medium was determined experimentally by measuring the acoustic emission signal processed from the workpiece placed in a specific location in the machining zone cross section.

Owing to the results of simulation studies [1], the authors knew what distribution should be expected and that it could limit the number of measurement points. However, in order to fully verify the results of the simulation tests and to estimate the functional dependencies with greater accuracy, it was decided to do measurements in the whole cross section of working medium, with the accuracy of $5 \mathrm{~mm}$ in the $\mathrm{X}$ and $\mathrm{Y}$ axes (assuming the workpiece size of at least $20 \mathrm{~mm}$ ).

The experimental tests made it possible to determine the relationship between the AE signal and the working medium energy in different locations and to find the region with the greatest energy for different machining conditions.

\subsection{Machine setup and experimental conditions}

All experiments were performed with the use of the following: an EC6-WET disc finishing machine (ZMM "Avalon" Wojciech Gibuła, Poland); $1.2 \mathrm{~kg}$ of abrasive plastic chips (particles); a workpiece, $20 \mathrm{~mm}$ in diameter, made of brass; and an acoustic emission data acquisition system composed of an 8152B211 piezoelectric AE sensor, a 5125B2 coupler (Kistler Holding AG, Switzerland), and a high-performance modular PXIe-1073 system (with a PXIe-6124 multifunction DAQ 16-bit converter) by National Instruments Corp. (USA) (Fig. 5).

The EC6-WET centrifugal disc finishing machine (Fig. 5a) is a device used for the simultaneous mass machining of approximately $0.5 \mathrm{~kg}$ of workpieces, with a total working bowl capacity of 61 and an effective working bowl diameter of $210 \mathrm{~mm}[10,11]$. The device enables the execution of such processes as deburring, rounding edges, cleaning, smoothing, removing tarnish, rough and finish grinding, and polishing, 


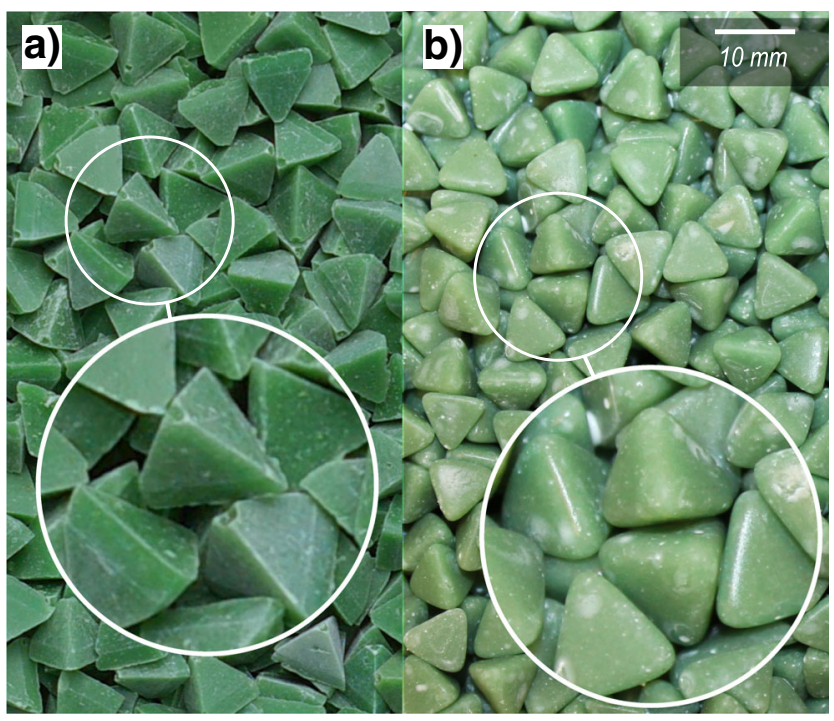

Fig. 6 Abrasive particle type T10PP (MARBAD, Poland) with a resin bond. a New with sharp edges. b Used with rounded edges (after 20-h work)

using ceramic, resin, porcelain, and steel particles. The process can be either dry or wet.

The experimental tests were conducted using 3500 abrasive particles (Fig. 5b) with a resin bond, characterized by a density of $1.6 \mathrm{~g} / \mathrm{cm}^{3}$. The particles were pyramid-shaped (Fig. 6) with an edge length of $10 \mathrm{~mm}$. A single abrasive particle has a volume of approximately $220 \mathrm{~mm}^{3}$. The brand of the producer (MARBAD, Poland) was T10PP while that of the distributor (AVALON, Poland) was 02PP10. The abrasive particles wear out over time, resulting in rounded edges (Fig. $6 b)$. For this reason, they need to be replaced regularly. New, sharp particles were used in all experiments.

Particles with a resin bond are basic machining products used in disc finishing machines in the machining of nonferrous metal ( $\mathrm{Al}, \mathrm{Mg}, \mathrm{ZnAl}$, brass) or plastic parts, where delicate machining is required.

A liquid compound, namely ASP-R (MARBAD, Poland), which absorbs the resulting waste and removes the remains of particles and the material cut, was used in the smoothing process. The chemical compounds present in the solution decrease the surface tension (as a penetrant), have an antifoaming effect (reduce the foam created in the machining process), and create a tribofilm on the surface of the material machined, particles, and inside the walls of the working bowl of the centrifugal disc finishing machine. This layer makes it easier to separate the abrasive particles and limits their wear (a mutual contact between particles is responsible for $75 \%$ of their wear).

The measurement system, whose main element is the 8152B211 sensor, is highly sensitive to the Rayleigh surface and longitudinal waves in a wide frequency range, up to $900 \mathrm{kHz}$ (producer's data); cf. Table 1.

\subsection{Methodology of experimental tests}

The aim of the experimental tests was to determine locations with the greatest energy level in a transverse section of the working medium composed of abrasive particles. A measurement sample made from brass (copper-zinc-lead alloy:

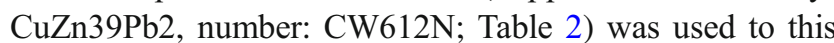
end, characterized by special geometry (to reduce the disturbances of the medium by a fixture part) and a round impact area with a diameter of $20 \mathrm{~mm}$ (and 1-mm thick).

Copper-zinc-lead alloys have very good machinability and cold workability, as well as excellent forgeability and freecutting qualities. A variety of copper and lead content levels provide a choice of optimum combinations of ductility, formability, and machinability to suit a very wide range of enduses. The CW612N alloy is the standard used for forgings requiring extensive machining, architectural hardware, fittings, mechanical components, and specialty fasteners.

The measurement sample was moved inside the disc finishing machine working zone, recording the working medium impacts in various locations in relation to the cross section of the rotating working medium. A system permitting a vertical and horizontal movement of the sample in a $2 \mathrm{D}$ setting with a precision level of 0.01 and $0.5 \mathrm{~mm}$, respectively, was used to this end (Fig. 5c). Three rotational speeds were used in the tests: 150,300 , and $450 \mathrm{rpm}$. The flow rate of the liquid compound supporting the machining was $450 \mathrm{ml}$ per hour (cf. Table 3).

Experimental studies were aimed at monitoring the polishing process by means of analyzing the emission of the

Table 1 Technical data of 8152B211 acoustic emission sensor and 5125B2 Piezotron coupler (manufacturer's data) [12, 13]

8152B211

\section{Sensitivity}

Frequency range $\pm 10 \mathrm{~dB}$

Sensing element

Shock limit

Temperature range operating

Output impedance
5125B2

$\begin{array}{ll}\text { AE frequency range (unfiltered) } & 5 \text { to } 1700 \mathrm{kHz} \\ \text { AE integration time constant (RMS) } & 1.2 \mathrm{~ms} \\ & \\ \text { Accuracy } & 5 \% \\ \text { Noise } & <10 \mathrm{mV}_{\mathrm{pp}} \\ \text { Output impedance (RMS) } & 10 \Omega\end{array}$

$48 \mathrm{dBref} 1 \mathrm{~V} /(\mathrm{m} / \mathrm{s})$
100 to $900 \mathrm{kHz}$
Ceramic
$2000 g_{0}$
-40 to $60{ }^{\circ} \mathrm{C}$
$<10 \Omega$


high-frequency stress waves occurring in the machining zone. The piezoelectric sensor was mounted on the top side of the workpiece holder. Raw AE impulses and RMS (root mean square values of $\mathrm{AE}$ ) signals were sampled in a digital form at the frequency of $f_{s}=4 \mathrm{MHz}$ per channel with a 16-bit resolution. For comparative and statistical purposes, the studies were carried out in different conditions and repeated five times.

The distribution of energy in the working stream of abrasive particles depends on their local velocity, which at the same time determines the value of kinetic energy of a single particle. This energy is a resultant of many factors and technological parameters of the process, mainly related to the rotational speed of the working chamber rotor, the mass of abrasive medium, and the interaction between particles.

When an abrasive particle impacts the workpiece surface, part of the kinetic energy is converted into deformation of the machined material. In general, it is obvious that the greater the impact energy is (identified with the local energy of the working medium), the greater the deformation of the object is. This deformation, in the form of an elastic wave, is propagated by the entire volume of the workpiece material and, under certain conditions, reaches the outer surface of this material, where it can be measured in the form of a surface acoustic wave (known as the Rayleigh wave) by a piezoelectric transducer. The voltage measured on the piezoelectric sensor can be expressed by the following equation [14]:

$u=\frac{h_{p}}{s_{f}}\left[v_{1}-v_{2}\right]+\frac{1}{C_{0} s_{f}} i$,

where $v$ is the velocity of surface particles in the wave deflected by $\zeta$ value, $v_{1}$ is the initial velocity $v(0), v_{2}$ is the velocity for a given deflection $v(\zeta), i$ is the electric current, $h_{p}$ is the piezoelectric constant, $s_{f}$ is the complex frequency, and
$C_{0}$ is capacitance between piezoelectric electrodes.

The displacement of molecules in the wave is related to their velocity:

$\varsigma=\frac{v}{s_{f}}$

therefore, the electric field is related in proportion to the change of this displacement [16]:

$E_{f}=-h_{p} \frac{d \varsigma}{d z}+\frac{1}{\varepsilon} D_{f}$,

where $\varepsilon$ is the permittivity and $D_{f}$ is the electric displacement field.

The above analyses indicate a close relationship between the energy of abrasive particles and the recorded voltage on piezoelectric sensors.

A map of the working medium's energy distribution was created on the basis of the specific values of AE signal energy recorded at specific measurement points. The AE signal energy value, determined by measuring the root mean square of the voltage signal recorded by the piezoelectric sensor, depends on the energy of the signal source that generated the specific impulse, on the attenuation rate of the center in which the signal was diffused, and on the distance between the sensor and the signal source. Since both the center of acoustic wave diffusion and the distance from the signal source were constant throughout the whole experiment, it should be expected that the recorded values of AE signal amplitude depend solely on the source energy and that they are proportional to that energy.

The signal root mean square value is one of the basic parameters of the periodically variable signal, and it is a frequently used estimator, in particular, in the case of an analysis of complex signals, i.e., vibrations or noise. The RMS of the

Table 2 Chemical composition and selected typical physical and mechanical properties of copper-zinc-lead alloy (brass) sheet according to EN 1652 $[14,15]$

\begin{tabular}{|c|c|c|c|c|c|}
\hline ISO/EN/AFNOR/PN/DIN & \multicolumn{2}{|l|}{ EN-AW } & \multirow{2}{*}{$\begin{array}{l}\text { UNS } \\
\text { C37700 }\end{array}$} & \multirow{2}{*}{$\begin{array}{l}\text { BS (old) } \\
\text { CZ120 }\end{array}$} & \multirow{2}{*}{$\begin{array}{l}\text { PN (old) } \\
\text { MO59 }\end{array}$} \\
\hline $\mathrm{CuZn39Pb2}$ & CW612N & & & & \\
\hline \multicolumn{6}{|c|}{ Chemical composition and percentage of elements (wt\%) } \\
\hline $\mathrm{Cu} \quad \mathrm{Pb}$ & $\mathrm{Al}$ & $\mathrm{Fe}, \mathrm{Ni}, \mathrm{Sn}$ & $\mathrm{Zn}$ & $\mathrm{P}, \mathrm{Si}, \mathrm{As}, \mathrm{Mn}, \mathrm{Sb}$ & Others \\
\hline $1.6-2.5$ & Max 0.05 & Max 0.3 & Remainder & - & Max 0.2 \\
\hline \multicolumn{6}{|c|}{ Physical and mechanical properties } \\
\hline Density & \multicolumn{2}{|l|}{$8.4-8.7 \mathrm{~g} / \mathrm{cm}^{3}$} & \multicolumn{2}{|c|}{ Machinability index ${ }^{*}$} & $80 \%$ \\
\hline Elasticity modulus & \multicolumn{2}{|l|}{$120-125 \mathrm{GPa}$} & \multicolumn{2}{|c|}{ Thermal conductivity (at room temperature) } & $120 \mathrm{~W} / \mathrm{mK}$ \\
\hline Specific heat & \multicolumn{2}{|l|}{$377 \mathrm{~J} /(\mathrm{kg} \mathrm{K})$} & \multicolumn{2}{|c|}{ Electrical conductivity } & $27 \%$ IACS \\
\hline Coeff of thermal expansion & \multicolumn{2}{|l|}{$21.1 \cdot 10^{-6} / \mathrm{K}$} & \multicolumn{2}{|c|}{ Melting point } & $880-895{ }^{\circ} \mathrm{C}$ \\
\hline $0.2 \%$ proof strength $\left(R p_{02}\right)$ & \multicolumn{2}{|l|}{$170-495 \mathrm{MPa}$} & \multicolumn{2}{|c|}{ Ultimate tensile strength $\left(R_{m}\right)$} & $420-590 \mathrm{MPa}$ \\
\hline Hardness & \multicolumn{2}{|l|}{ 110-185 HV } & \multicolumn{2}{|c|}{ Elongation $(A)$} & $30-5 \%$ \\
\hline
\end{tabular}

* The evaluation of machinability is not an absolute measured value. It rather is a comparative rating $(\mathrm{CuZn} 39 \mathrm{~Pb} 3=100 \%)$ 
Table 3 Machining parameters

\begin{tabular}{lll}
\hline $\begin{array}{l}\text { Rotating speed } \\
\operatorname{rpm}\left(\mathrm{rad} / \mathrm{s}^{*}\right)\end{array}$ & $\begin{array}{l}\text { Liquid compound flow rate } \\
\text { ml per hour }\end{array}$ & $\begin{array}{l}\text { Mass of plastic chips } \\
\mathrm{kg}\end{array}$ \\
\hline $150(15.71), 300(31.42), 450(47.12)$ & 450 & 1.2 \\
\hline
\end{tabular}

* Rotational speed (in $\mathrm{rad} / \mathrm{s}$ ) specified for the needs of the simulation model

current and periodically variable signal voltage is calculated on the basis of the following equations:

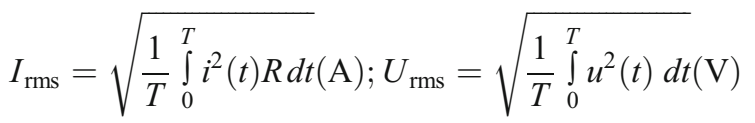

Since the instantaneous power of a periodic signal varies over time, this power, which includes audio power, is measured as an average over time:

$P_{\mathrm{avg}}=\frac{1}{T} \int_{0}^{T} P_{s}(t) d t=\frac{1}{T} \int_{0}^{T} u(t) \cdot i(t) d t=\frac{1}{R T} \int_{0}^{T} u^{2}(t) d t$.

Average power can also be estimated using the RMS value:

$P_{\mathrm{avg}}=I_{\mathrm{rms}} R=\frac{U_{\mathrm{rms}}^{2}}{R}(\mathrm{~V} \cdot \mathrm{A}=\mathrm{W})$.

For analog signals, we define power as energy per time interval. The root mean square is proportional to signal energy:

$$
\begin{aligned}
P_{s} & =E_{s} / T \Rightarrow E_{s}=P_{s} \cdot T=\frac{U_{\mathrm{rms}}^{2}}{R} T \\
& =\frac{1}{R} \int_{t_{0}}^{t_{0}+T} u^{2}(t) d t(\mathrm{~J}=\mathrm{W} \cdot \mathrm{s}=\mathrm{V} \cdot \mathrm{A} \cdot \mathrm{s}) .
\end{aligned}
$$

The energy of a discrete-time signal is defined as follows:

$$
E_{S}=\sum_{n_{\mathrm{sq}}=-\infty}^{\infty}\left|x\left(n_{\mathrm{sq}}\right)\right|^{2} \text { or } E_{S}\left(i_{\mathrm{f} r}\right)=\sum_{n_{\mathrm{sq}}=1}^{W_{L}}\left|x_{i(\mathrm{f} r)}\left(n_{\mathrm{sq}}\right)\right|^{2}
$$

and normalized as:

$E_{S}\left(i_{\mathrm{fr}}\right)=\frac{1}{W_{L}} \sum_{n_{\mathrm{sq}}=1}^{W_{L}}\left|x_{i(\mathrm{fr})}\left(n_{\mathrm{sq}}\right)\right|^{2}$,

where $x(i), n_{\mathrm{sq}}=1$ to $W_{L}$ is the sequence of signal samples of the $i_{\mathrm{fr}}$ th frame, where $W_{L}$ is the length of the frame. In fact, although Eq. 10 provides the so-called power of the signal, in many signal processing studies, the term "energy" is used for the sake of simplicity.

Because of this, the results of AE signal measurements were deemed to be representative for an analysis of the kinetic energy of the working medium.

\section{Results and discussion}

Analyzing the dynamics of the particles altogether, as the stream movement inside the working chamber of the centrifugal disc finishing machine, it was noted that the stream is a
Fig. 7 Visualization of the distribution of areas occupied by the stream of abrasive particles in the working chamber of the EC6WET machine at various rotational speeds

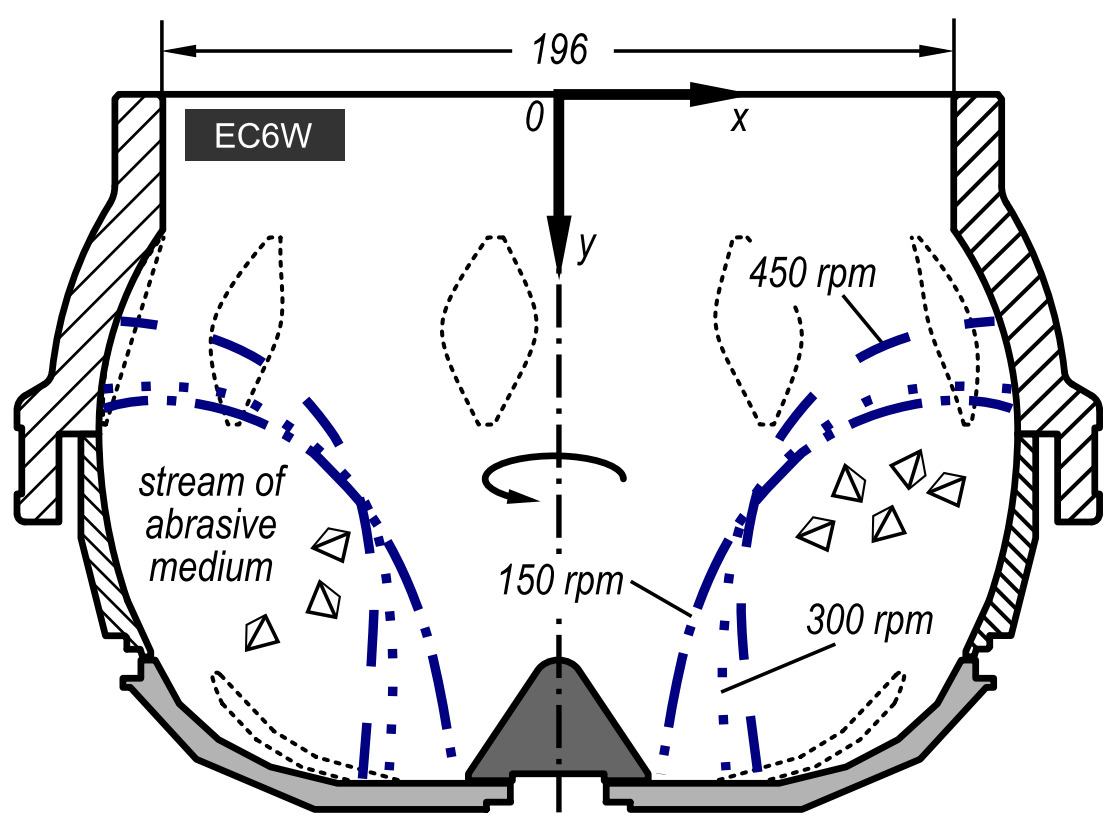



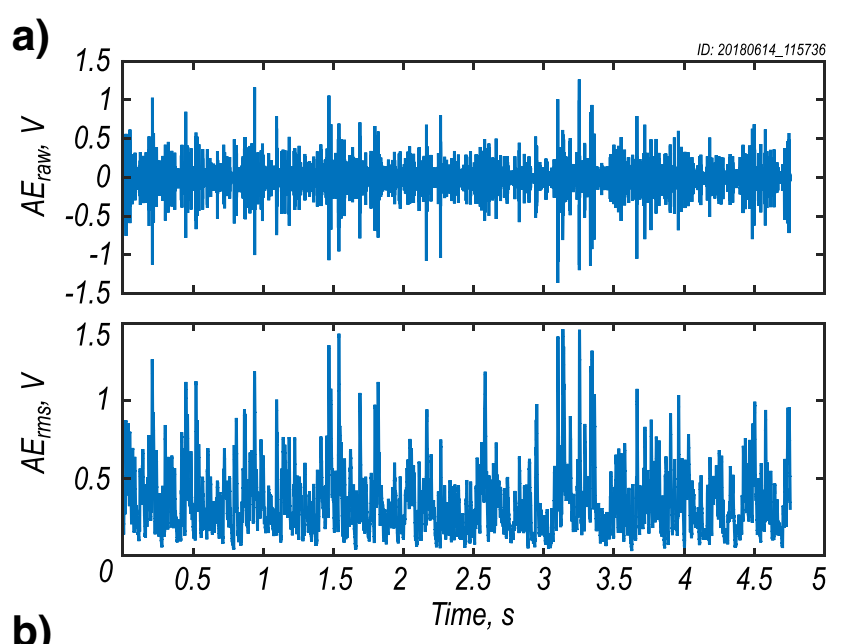

b)
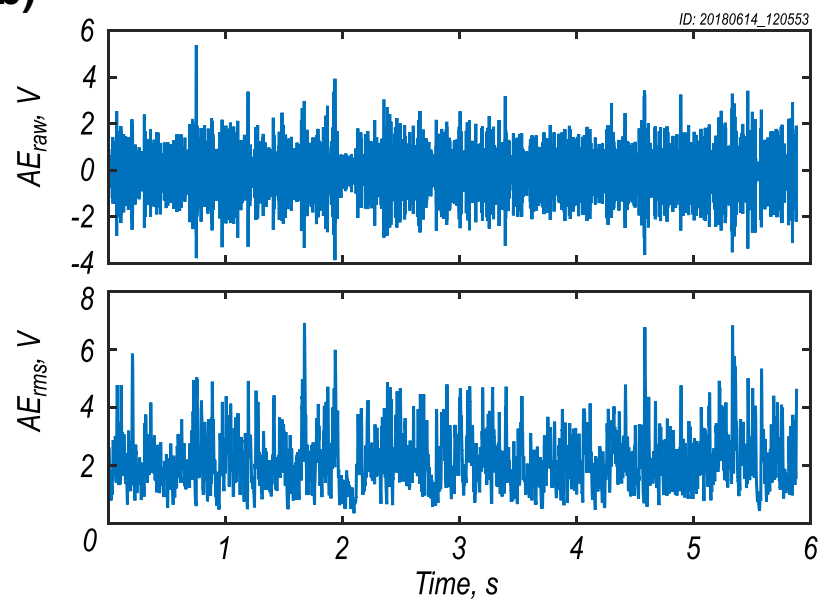

Fig. 8 Exemplary acoustic emission signals recorded at the working chamber rotor's speed $450 \mathrm{rpm}$. a In an area with low working stream energy. $\mathbf{b}$ In an area with relatively high stream energy

relatively static object. It has its relatively constant shape (the "slenderness" of the particles' distribution is presented in Fig. 7). It has been observed that the position and shape of the working medium depend on the rotational speed of the rotary disc. The higher the speed was, the higher the particles were lifted up in the working space of the working chamber. The abrasive particles also moved away from the axis of rotation in relation to the rotational speed. The same behavior of the particles was determined in simulation studies (Fig. 7 in the companion paper [1]).

The frequency signal, received from a measurement sample, placed in a specific location of the cross section of the working medium during its working motion, was used to record the energy. The measurements were executed with a 5-mm resolution, with different working speeds of the working medium composed of particles, which made it possible to establish locations with the greatest state of energy for specific technological conditions (cf. Figs. 8 and 9).

The amplitude of the AE signal recorded during the process clearly increases if the sample is located in an area with greater abrasive particle stream energy, which confirms the results of simulation tests. An increase in the AE impulses' amplitude is also clearly visible with the increase of the signal RMS value (bottom chart in Fig. 8), which is indicative of an increase in these impulses' energy.

The surface of the area of interest, that is the area that seems to be the most advantageous due to its location in the space of the disc finishing machine's working chamber and due to the high recorded AE signal values, was determined in the tests as constant, amounting to $400 \mathrm{~mm}^{2}$. Due to the phenomenon of a turbulent flow of the particles around the material machined, an ROI location could not be selected in the place of contact with the working chamber, in particular near the rotor drivers. An area satisfying these conditions was sought within the particle stream. Diagrams presented in Fig. 9 have two areas marked on them, a)

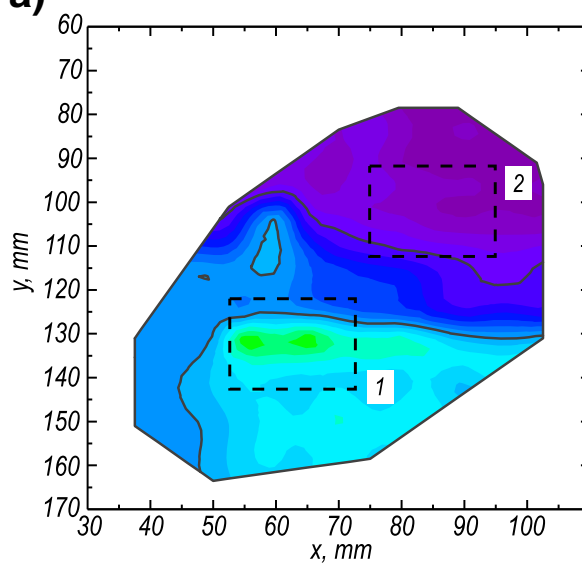

b)

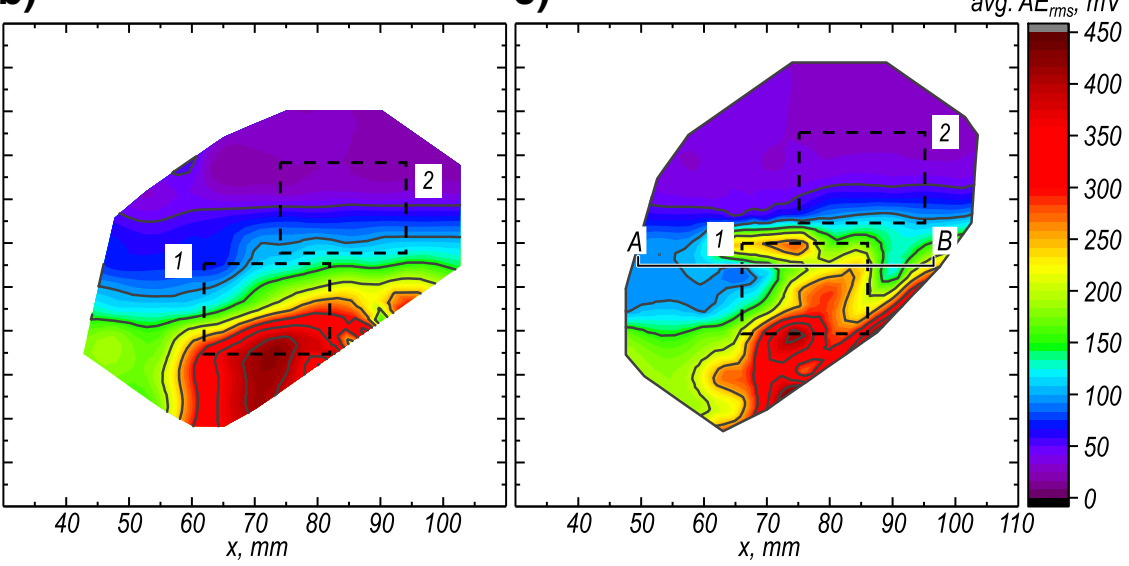

Fig. 9 Maps of the distribution of average AE signal RMS values in the abrasive particle stream and the indicated analyzed areas of low (\#2) and high energy (ROI, \#1), measured at different rotational speeds. a $n=$
$150 \mathrm{rpm}$. b $300 \mathrm{rpm}$. c $450 \mathrm{rpm}$ (measurement density in axes $\mathrm{X}$ and $\mathrm{Y}$ : $5 \mathrm{~mm}$; line $\mathrm{AB}$ - measuring section for spectrogram) 
Table 4 Comparison of results of signal RMS value measurement at different rotational speeds

\begin{tabular}{lccccc}
\hline$n(\mathrm{rpm})$ & \multirow{2}{*}{$\operatorname{Avg} A E_{\mathrm{rms}}$} & Avg power $P_{S}$ & Avg energy $E_{s}$ & \multicolumn{2}{c}{ Area of high values in ROI (\#1) } \\
\cline { 4 - 6 } & $\mathrm{mV}$ & $\mathrm{mW}$ & $\mathrm{mJ}$ & $\mathrm{mm}^{2}$ & $\%$ \\
\hline 150 & $792( \pm 34)$ & $38.1( \pm 2.7)$ & $228.6( \pm 16.2)$ & 75.9 & 19.0 \\
300 & $1472( \pm 126)$ & $177.2( \pm 25.9)$ & $1063.2( \pm 155.8)$ & 303.6 & 75.9 \\
450 & $1307( \pm 107)$ & $143.7( \pm 20.6)$ & $862.4( \pm 123.7)$ & 349.1 & 87.3 \\
\hline
\end{tabular}

namely, 1-an ROI area with high machining potential and 2-an exemplary area with low AE signal energy.

A large number of analyses of the acoustic emission signal were conducted for both areas being compared in order to establish the differences between these locations. Table 4 contains results for area 1 , which is an area of interest with relatively high energy.

The method of determining a surface with high energy in the area of interest is presented (AHV (Area of High Values)) in Fig. 10. It consisted of determining the borders of the area where high $A E_{\mathrm{rms}}$ parameter values, as compared with the other parts, were noted. Places that did not fall within the blue-shaded part of the scale were not included in this area.

Analyzing the share of high signal values $A E_{\mathrm{rms}}$ in the cross-sectional area of the ROI, it was demonstrated that as the rotational speed of the disc finishing machine's spindle increases, the share of high values grows. At a rotational speed of $150 \mathrm{rpm}$, this is $75.9 \mathrm{~mm}^{2}$, which constitutes only $19 \%$ of the designated area. At a speed of $n=300$ and $450 \mathrm{rpm}$, the share increases to $75.9 \%$ and $87.3 \%$, respectively. This means that with the fixed size of the workpieces, a higher rotational speed guarantees not only the transmission of greater energy to the material surface but also more even machining.

Although the average value of the amplitude of the $A E_{\mathrm{rms}}$ signal and those remaining (power and energy) in the entire stream of abrasive particles depends on the rotational speed of the disc finishing machine's rotor, it is not a parameter that increases proportionally (statistically speaking) with an increase in speed $n$. At the highest rotational speed, the average stream value clearly decreased as compared with a speed of $300 \mathrm{rpm}$.

Changes in the mean value of parameter $A E_{\mathrm{rms}}$ measured in the area of interest with a relatively high machining potential have a different, advantageous nature as far as process monitoring and supervision are concerned. Recorded AE signal RMS values (Table 5) increase with the rotational speed value: from $1.32 \mathrm{~V}$ for $150 \mathrm{rpm}$ up to $2.94 \mathrm{~V}$ for $450 \mathrm{rpm}$. This corresponds to a change in the discrete signal energy from $157.9 \times$ $10^{-4} \mathrm{~V}^{2}$ to $705 \times 10^{-4} \mathrm{~V}^{2}$. The value increases are considerable. The greatest increase is observed upon changing the speed from 300 to $450 \mathrm{rpm}$. Regarding the average $A E_{\mathrm{rms}}$ value, this is an increase of $62 \%$ (127\% for the signal energy). This means that the typical $A E_{\mathrm{rms}}$ value observed in the recorded signal increases considerably and can be successfully used to monitor and supervise the smoothing process, indicating the machining potential of the working medium.

The increases are not as significant for the raw signal $\left(A E_{\text {raw }}\right)$ : by $69 \%$ upon changing the speed from $n=150 \mathrm{rpm}$ to $300 \mathrm{rpm}$, and $30 \%$ more upon increasing the speed $450 \mathrm{rpm}$.

The $Z_{\mathrm{CR}}$ parameter presents the number of times the signal changes value, from positive to negative and vice versa, divided by the length of the frame. The values of this parameter drop if the signal carries more information and less noise. In the case of the conducted experimental tests, the $Z_{\mathrm{CR}}$ parameter value's drop results from an increase in the elementary phenomena that participate in shaping the AE signal along with an increase in the machine rotor's rotational speed. Although changes in the $Z_{\mathrm{CR}}$ value and sound pressure level (SPL) are determinable, they are relatively low, namely a few or several percent.

The results presented in Table 5 are also indicative of considerable differences between the values of acoustic emission descriptors during measurement in different parts of the abrasive particle stream. The values of AE signal amplitude and parameters related to the signal's energy (root mean square, instantaneous energy, sound pressure level) clearly increase if

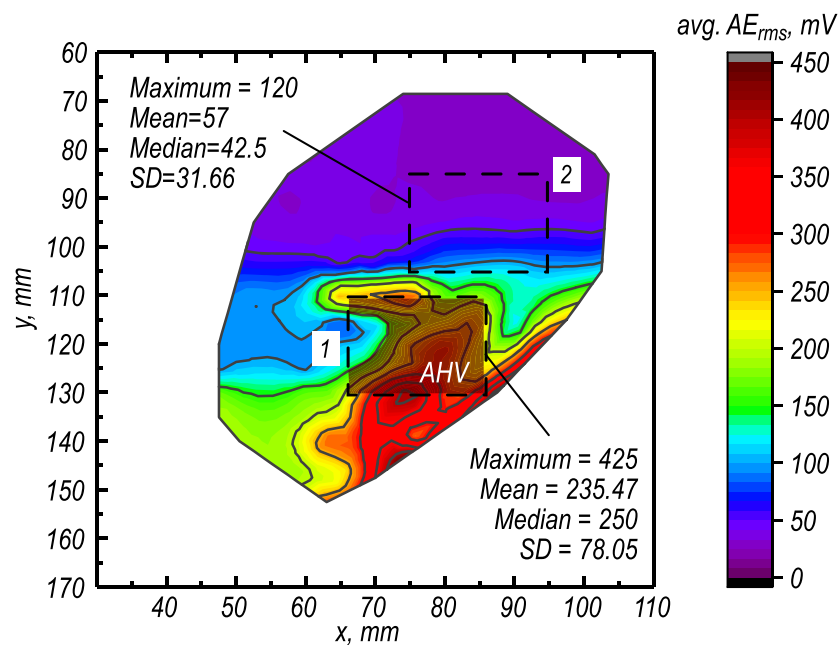

Fig. 10 Example of determining AHV in the area of interest presented at the working chamber rotational speed $450 \mathrm{rpm}$ 
Table 5 Average values of time-domain features of AE signal acquired during polishing brass surface in EC6-WET disc finishing machine

\begin{tabular}{|c|c|c|c|c|c|}
\hline$n(\mathrm{rpm})$ & $\begin{array}{l}\text { Raw signal } \\
A E_{\text {raw }}(\mathrm{V})\end{array}$ & $\begin{array}{l}\text { Root mean } \\
\text { square value } \\
A E_{\mathrm{rms}}(\mathrm{V})\end{array}$ & $\begin{array}{l}\text { Sound pressure } \\
\text { level (SPL) } \\
S(\mathrm{~dB}) \text { ref. 20e-6 }\end{array}$ & $\begin{array}{l}\text { Short-time energy } \\
\text { (STE)* } \\
E_{\mathrm{STE}}\left(10^{-4} \mathrm{~V}^{2}\right)\end{array}$ & $\begin{array}{l}\text { Zero-crossing rate } \\
\text { (ZCR) } \\
Z_{\mathrm{CR}}\left(10^{-3}\right)\end{array}$ \\
\hline \multicolumn{6}{|c|}{ ROI area with low machining potential } \\
\hline 150 & $0.29( \pm 0.06)$ & $0.35( \pm 0.01)$ & $28.70( \pm 0.45)$ & $6.8( \pm 0.7)$ & $19.0( \pm 0.6)$ \\
\hline 300 & $0.52( \pm 0.09)$ & $0.88( \pm 0.11)$ & $37.28( \pm 0.27)$ & $49.3( \pm 3.1)$ & $19.8( \pm 0.09)$ \\
\hline 450 & $0.53( \pm 0.16)$ & $0.74( \pm 0.08)$ & $33.96( \pm 0.18)$ & $22.9( \pm 0.9)$ & $21.3( \pm 0.08)$ \\
\hline \multicolumn{6}{|c|}{ ROI area with high machining potential } \\
\hline 150 & $0.71( \pm 0.11)$ & $1.32( \pm 0.07)$ & $42.33( \pm 0.15)$ & $157.9( \pm 5)$ & $21.4( \pm 0.17)$ \\
\hline 300 & $1.20( \pm 0.06)$ & $1.81( \pm 0.15)$ & $45.27( \pm 0.17)$ & $310.7( \pm 12)$ & $19.5( \pm 0.19)$ \\
\hline 450 & $1.57( \pm 0.17)$ & $2.94( \pm 0.32)$ & $48.80( \pm 0.19)$ & $705.0( \pm 32)$ & $16.3( \pm 0.14)$ \\
\hline
\end{tabular}

${ }^{*}$ Calculated according to Eq. 9

the machining takes place in an area of a greater machining potential. This means that seeking their highest values (during the process monitoring) can be used to boost the machining effectiveness and shorten the machining duration. As far as the energy signal $\left(E_{\mathrm{STE}}\right)$ is concerned, the greatest increase is over 220 times at a speed of $n=150 \mathrm{rpm}$ (from $6.8 \cdot 10^{-4}$ to 157.9 . $10^{-4} \mathrm{~V}^{2}$ ), nearly 500 times at $300 \mathrm{rpm}$ and almost 300 times at
$450 \mathrm{rpm}$ (the highest examined speed of the working chamber rotor).

The above result of experimental tests is proof of energy differences occurring in the working stream, regardless of the machining parameters applied.

The correlation between the described parameters and rotational speed of the working chamber rotor was calculated a)

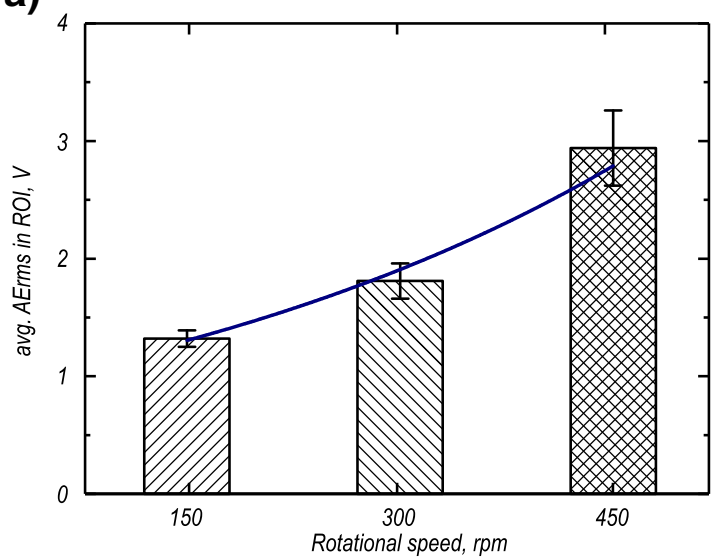

c)

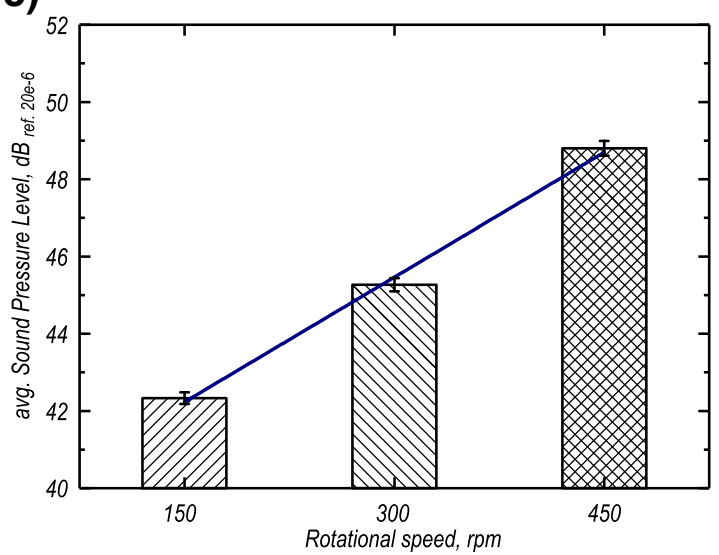

b)

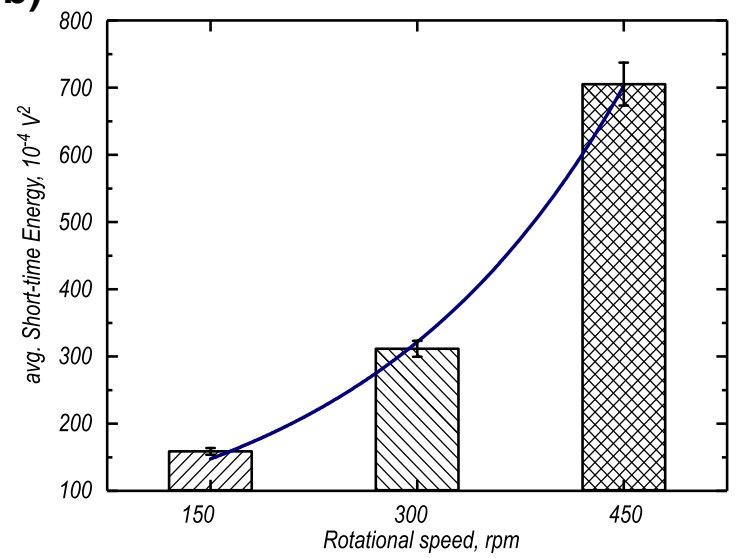

d)

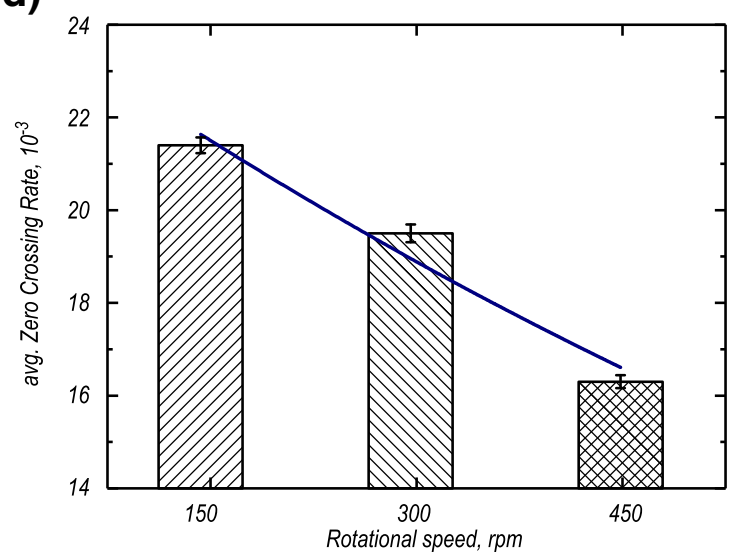

Fig. 11 Characteristics of the ROI area with a high machining potential depending on the spindle's rotational speed. Average values of a root mean square value of $\mathrm{AE}, \mathbf{b}$ short-time energy of $\mathrm{AE}$ signal, $\mathbf{c}$ sound pressure level of $\mathrm{AE}$ signal, $\mathbf{d}$ zero-crossing rate for $\mathrm{AE}$ signal 
Table 6 Parameters and statistics of the fit functions for time-domain descriptors of AE signal

\begin{tabular}{|c|c|c|c|c|c|}
\hline Eq. & Parameter & Value & Standard error & $t$ value & Prob $>|t|$ \\
\hline \multirow[t]{3}{*}{11} & a & 0.705 & 0.096 & 7.29 & 0.087 \\
\hline & $\mathrm{b}$ & 0.008 & $3.8 \times 10^{-4}$ & 23.06 & 0.028 \\
\hline & \multicolumn{2}{|c|}{ Adj R-square, 0.9959} & \multicolumn{3}{|c|}{$F$ value, $5616.2 ;$ prob $>F=0.008$} \\
\hline \multirow[t]{3}{*}{12} & a & 0.892 & 0.073 & 12.23 & 0.052 \\
\hline & $\mathrm{b}$ & 1.002 & $3.2 \cdot 10^{-4}$ & 3105.98 & $2 \cdot 10^{-4}$ \\
\hline & \multicolumn{2}{|c|}{ Adj. R-square, 0.9550} & \multicolumn{3}{|c|}{$F$ value, $421.7 ;$ prob $>F=0.031$} \\
\hline \multirow[t]{3}{*}{13} & $\mathrm{a}$ & 146.51 & 0.171 & 858.30 & 0.034 \\
\hline & $\mathrm{b}$ & 60.74 & 0.385 & 157.73 & 0.034 \\
\hline & \multicolumn{2}{|c|}{ Adj. R-square, 0.9996} & \multicolumn{3}{|c|}{$\boldsymbol{F}$ value, $12881.4 ;$ prob $>F=0.006$} \\
\hline \multirow[t]{3}{*}{14} & a & 38.99 & 0.368 & 105.99 & 0.006 \\
\hline & $\mathrm{b}$ & 0.022 & 0.001 & 18.99 & 0.033 \\
\hline & Adj. R-squ & & \multicolumn{3}{|c|}{$F$ value, $53627.6 ;$ prob $>F=0.003$} \\
\hline \multirow[t]{3}{*}{15} & $\mathrm{a}$ & 4.20 & 0.110 & 38.13 & 0.017 \\
\hline & $\mathrm{b}$ & 0.005 & $2 \cdot 10^{-4}$ & 19.95 & 0.032 \\
\hline & Adj. R-squ & & \multicolumn{3}{|c|}{$F$ value, $1297.4 ;$ prob. $>\boldsymbol{F}=0.018$} \\
\hline \multirow[t]{3}{*}{16} & a & 24.69 & 1.235 & 20.003 & 0.032 \\
\hline & $\mathrm{b}$ & 0.999 & $1.6 \cdot 10^{-4}$ & 5984.02 & $1 \cdot 10^{-4}$ \\
\hline & \multicolumn{2}{|c|}{ Adj. R-square, 0.9328} & \multicolumn{3}{|c|}{$F$ value: $1235.8:$ prob $>F=0.018$} \\
\hline
\end{tabular}

statistically and presented in Fig. 11 in the form of bar charts and correlation lines.

The mean values of the $A E_{\mathrm{rms}}$ parameter and the others are closely correlated with the rotations of the working chamber rotor, which can be noted in two-parameter functions, namely:

$$
\operatorname{avg} \cdot A E_{\mathrm{raw}}=\ln (0.705+0.008 \cdot n)
$$$$
\operatorname{avg} \cdot A E_{\mathrm{rms}}=0.892 \cdot 1.002^{n} \text {, }
$$

a)

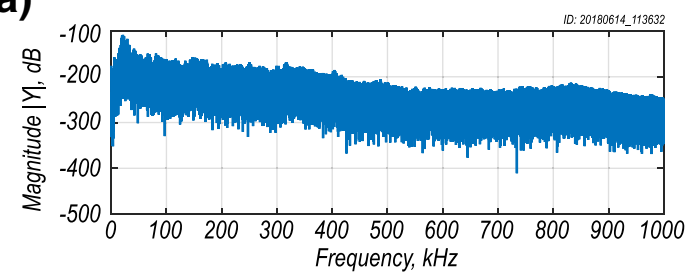

c)

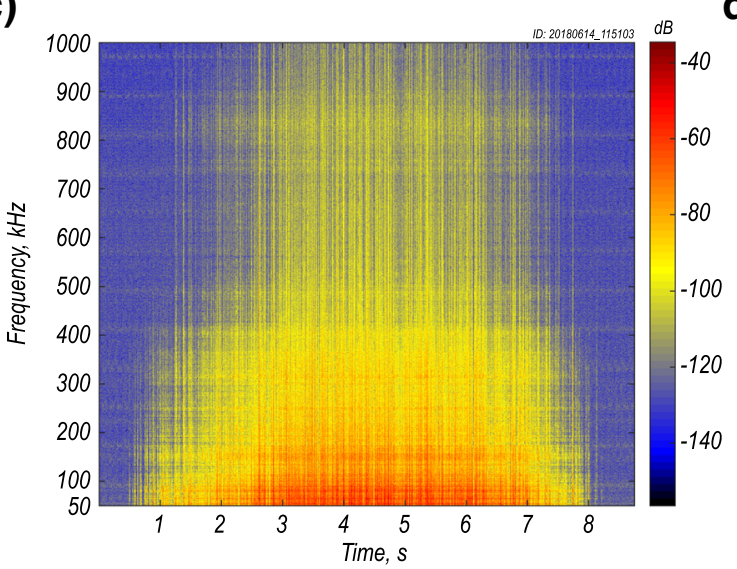

Fig. 12 Exemplary acoustic emission signals measured as a function of frequency for the working chamber rotor speed $450 \mathrm{rpm}$. a Signal spectrum in the area of low abrasive particle stream energy. b Signal spectrum in the area of relatively high stream energy. c AE signal b)

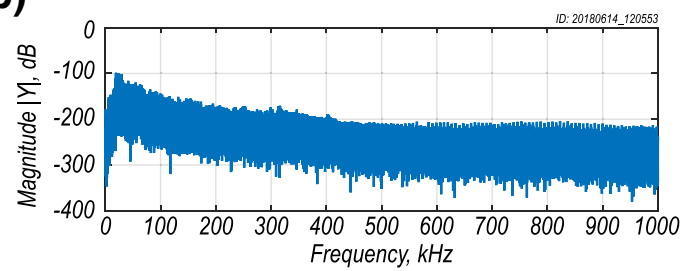

d)

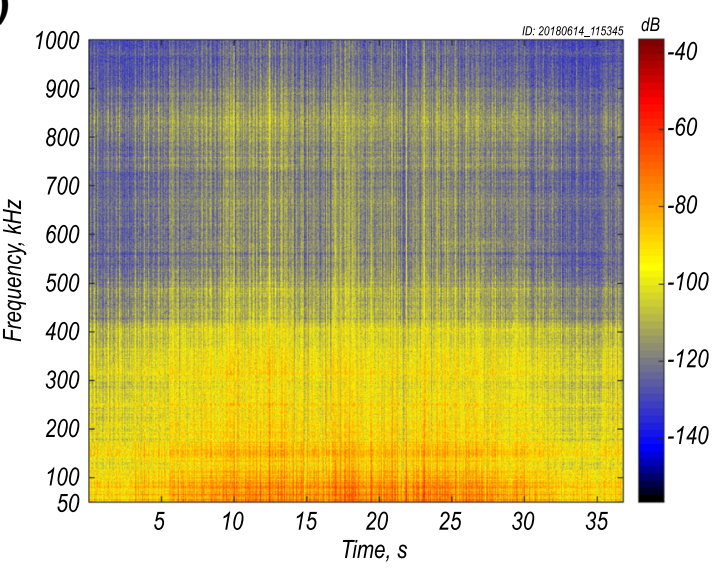

spectrogram in abrasive particle stream cross section (line AB in Fig. 9c) for $450 \mathrm{rpm}$. d AE signal spectrogram in ROI with high machining potential recorded with variable rotational speed $(n=150$ to $450 \mathrm{rpm}$ and in reverse) 
Table 7 Average values of frequency domain features of AE signal acquired during polishing of brass surface in EC6-WET disc finishing machine

\begin{tabular}{lll}
\hline & $\begin{array}{l}\text { Spectral centroid } \\
C(\mathrm{rpm})\end{array}$ & $\begin{array}{l}\text { Spectral entropy } \\
H \text { (arb. unit) }\end{array}$ \\
\hline \multicolumn{2}{l}{ ROI area with low machining potential } \\
150 & $0.13( \pm 0.002)$ & $0.218( \pm 0.02)$ \\
300 & $0.07( \pm 0.001)$ & $0.038( \pm 0.002)$ \\
450 & $0.08( \pm 0.0007)$ & $0.038( \pm 0.002)$ \\
ROI area with high machining potential & \\
150 & $0.076( \pm 0.001)$ & $0.093( \pm 0.006)$ \\
300 & $0.057( \pm 0.0003)$ & $0.043( \pm 0.001)$ \\
450 & $0.052( \pm 0.0006)$ & $0.024( \pm 0.001)$ \\
\hline
\end{tabular}

* Normalized in the range from 0 to 1 , where 1 corresponds to maximum possible signal frequency, i.e., $f_{s} / 2=2 \mathrm{MHz} .{ }^{* *}$ Calculated for $10 \mathrm{sub}-$ bands (bins)

$A_{\mathrm{HV}}=60.74 \ln (n-146.51)$,

$S=38.99+0.022 \cdot n$,

$E_{\mathrm{STE}}=\exp (4.20+0.005 \cdot n)$,

$Z_{\mathrm{CR}}=24.69 \cdot 0.999^{n}$.

The adjustment parameters of Eqs. 11-16 are presented in Table 6. All the equation forms were selected so that their parameters and the general model form were statistically significant. In all cases, low values of standard errors and values were noted, while statistical values $t$ and $F$ greater than the critical values for the assumed level of statistical significance $(\alpha=5 \%)$, indicated no reasons to reject the hypothesis of the parameters or the model's statistical significance.

In this paper, the widely used spectral-based approach was adopted, since it is effective for acoustic signal analysis.

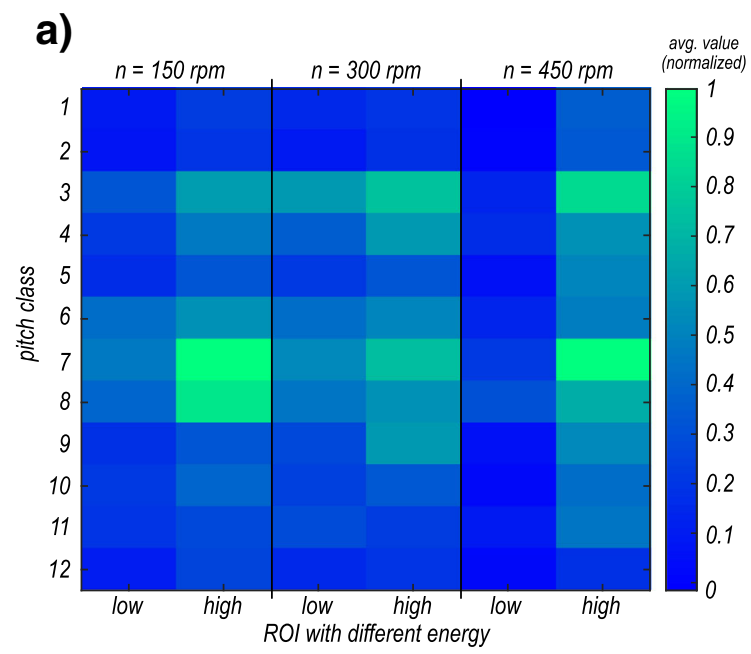

Fig. 13 Sound intensity analysis used to recognize differences in AE signals. a Chromagram obtained from the two different energy regions of the abrasive particle stream (for each rotation speed). b Medial value
Exemplary acoustic emission signals measured as a function of frequency for the highest speed of the working chamber rotor $(450 \mathrm{rpm})$ and recorded for the areas of low and high machining potential of the abrasive particle stream are presented in Fig. 12.

The distribution of harmonics in the signal (Fig. 12a, b) is typical of the experimental tests results obtained. A change in the measurement sample location is only indicative of an increase in magnitude. No changes were, however, observed in the distribution of specific frequencies. The same components have the same influence in creating the signal characteristic in all cases. The signal is strongly influenced by low acoustic emission components: up to $100 \mathrm{kHz}$. Harmonics in the range of 100 to $400 \mathrm{kHz}$ have a considerably lower influence. Components with shorter wavelengths (for surface waves, $\lambda_{S R}<4.8 \mathrm{~mm}$, and for longitudinal waves, $\lambda_{L}<11 \mathrm{~mm}$, assuming a rate of ultrasound waves propagation in brass of $1.95 \times 10^{3} \mathrm{~m} / \mathrm{s}$ and $4.43 \times 10^{3} \mathrm{~m} / \mathrm{s}$, respectively, for Rayleigh surface waves and longitudinal waves [17]) have a negligible influence on signal.

Figure $12 \mathrm{c}$ presents changes in the AE signal spectrum recorded for the rotational speed of the machine rotor in the case of its passing through the entire width of the abrasive particle stream, from the stream's internal edge to the external edge and back. Although changes in the magnitudes of specific harmonics are clearly visible in the signal spectrum, it is difficult to notice the occurrence of any characteristic frequencies for any of the stream areas. Similar conclusions were drawn in the case of analyzing the $\mathrm{AE}$ signal spectrum presented in Fig. 12d. The chart presents a signal spectrum in the case of maintaining a constant measurement sample location (in a location of high machining potential) and changing the rotational speed of the machine rotor from $n=150 \mathrm{rpm}$ to $450 \mathrm{rpm}$ and back. A detailed analysis of such signals requires

b)

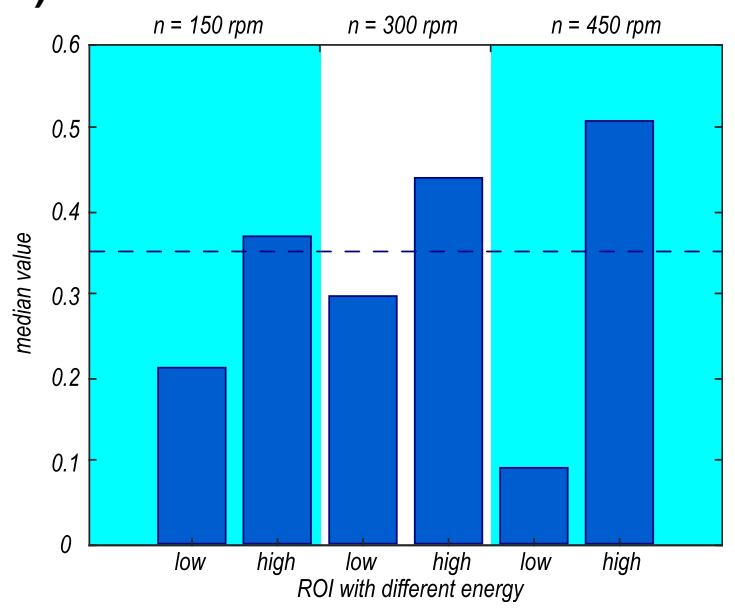

for all 12 pitch class for different rotation speed and position in stream (with the threshold level being marked) 


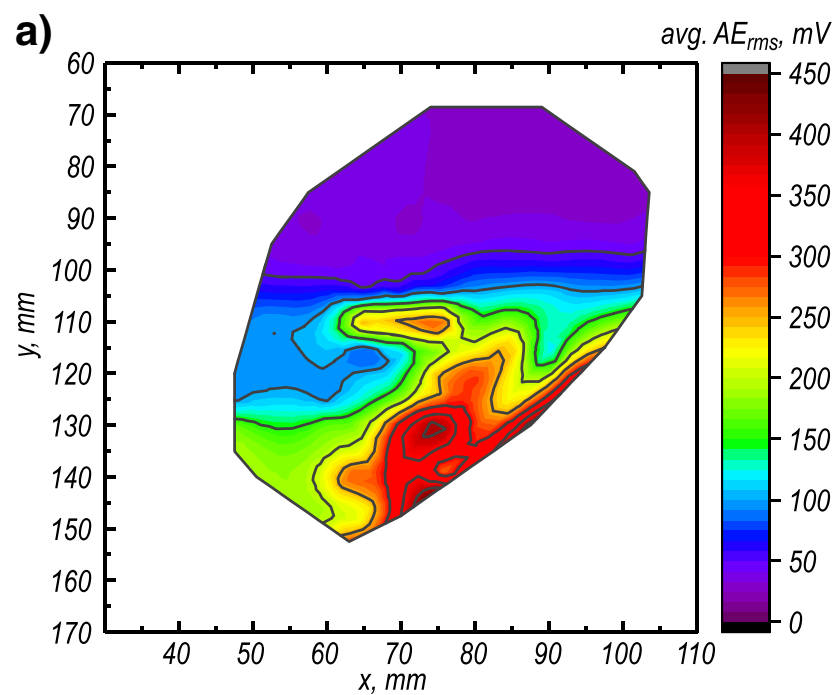

b)

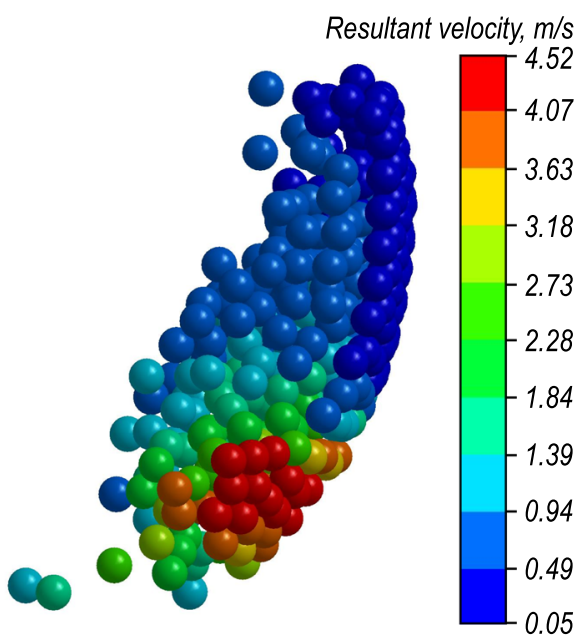

Fig. 14 Comparison of experimental and simulation results. a Average value of acoustic emission measured in working medium. b Resultant velocity in cross section of stream determined by DEM method (working chamber rotation speed $450 \mathrm{rpm}$, simulation time $4.69 \mathrm{~s}$ )

further research, e.g., related to a wavelet transform analysis and mel-frequency cepstral coefficients (MFCC), which can be helpful in determining the characteristic features of the $\mathrm{AE}$ signal for specific machining conditions.

The AE signal spectrum was analyzed using statistical analysis and by determining the center of gravity and spectral entropy. The results of these analyses are presented in Table 7.

The spectral centroid $(C)$ is the center of the "gravity" of the spectrum. The spectral centroid shifts to the left, towards lower frequencies upon passing from a low-energy area to an area with potentially higher machining effectiveness. The greatest difference is noticeable at a speed of $n=150 \mathrm{rpm}$. The centroid changes from 0.13 (approx $260 \mathrm{kHz}$ ) to 0.076 $(152 \mathrm{kHz})$. A change in the machine rotor's rotational speed has a similar impact on the nature of the AE signal and its spectrum: a drop in the $C$ parameters occurs and the rotational speed increases, though these changes are less considerable (a centroid change from 152 to $104 \mathrm{kHz}$ was observed for the ROI area with a higher machining potential). These changes can be described with a statistical model in the power formula:

$C=0.436 \cdot n^{-0.35}$

with adj R-square value equal to 0.8983 and $F$ value equal to 1132.2 .

The entropy of the normalized spectral energy $(H)$ can be interpreted as a measure of abrupt changes in the energy level of the signal. A single number characterizes the spectral entropy and, therefore, the information content of the signal (where 1 corresponds to a lack of information). The value can be used to efficiently compare signals. Results obtained in experimental tests prove that this parameter is inversely proportional to rotational speed $n$, which can be described with the following equation:
$H=-0.297 \ln (0.151 \cdot \ln n)$,

with adj R-square value equal to 0.9698 and $F$ value equal to 318.1 .

This means that a drop in the speed entails a drop in the AE spectral entropy. The energy concentration and increased "ordering level" of the signal spectrum are observed with higher speeds, which amount to boosting the information transmitted by the signal.

Figure 13 presents an analysis of sound intensity on the basis of the acoustic emission signals spectrum. This analysis is typical of musical sounds and recognizing signal patterns. The spectrum is converted from the frequency domain to the pitch domain by applying a log-frequency transformation. The distribution of energy along the twelve possible pitch classes is called a chromagram (analogous to a spectrogram), and it is presented in Fig. 13a.

The chromagram was generated as the mean value of sound intensity for each of the 12 classes for all the signals recorded divided into six groups which correspond to separate machining conditions (three rotational speeds and two measurement posts). The results indicate that shifting the measurement sample location towards the area of higher machining effectiveness increases the intensity of some classes. Although the sound pitch is increased, in particular, in class 7 , an increase is also discernible in classes 2,4 , and 8 . In order to increase the

Fig. 15 Comparison of the surface roughness and its isotropy for surfaces machined in different areas determined as high and low-energy areas by AE signal. The surface geometrical structure of workpieces machined in a high (a) and low (b) potential of the energy region. c Mean roughness profiles for different energy areas. Autocorrelation function and texture isotropy parameters determined for the surface geometrical structure of machined workpieces in a region with a high (d) and low (e) potential of energy 


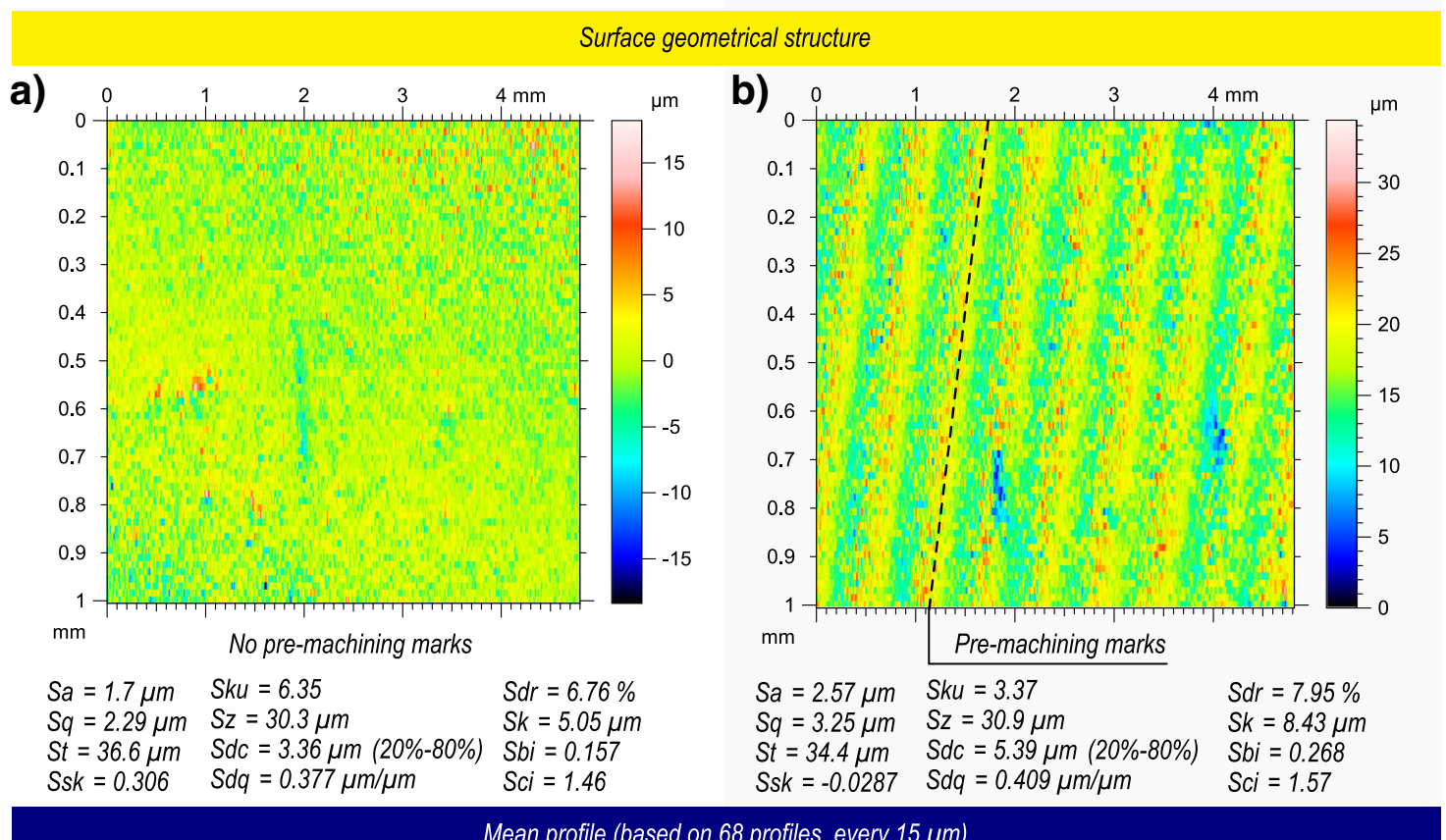

c)

Mean profile (based on 68 profiles, every $15 \mu \mathrm{m}$ )

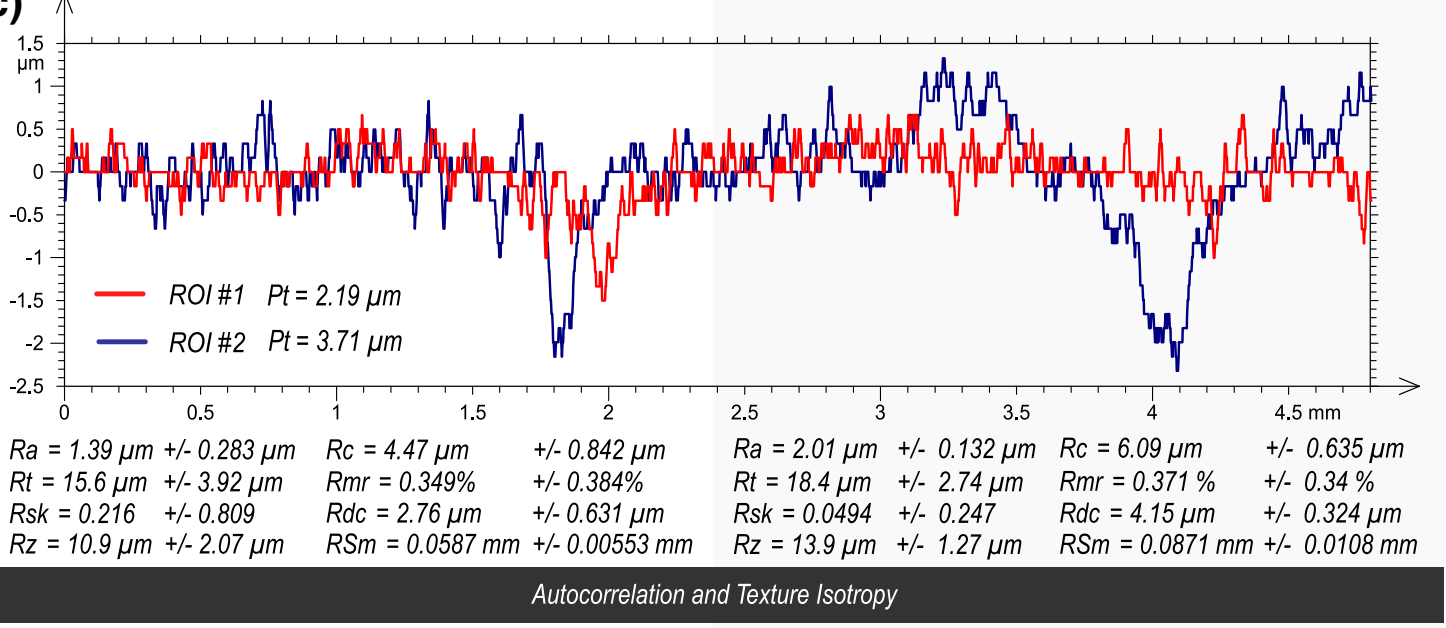

d)

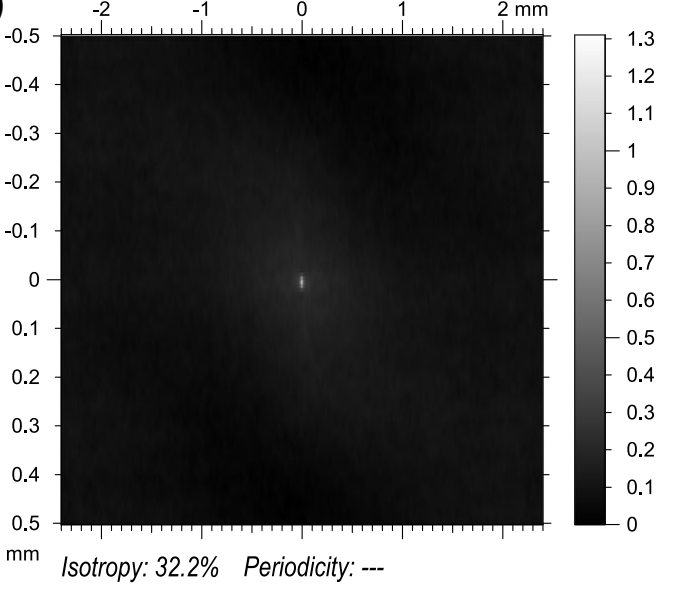

e)

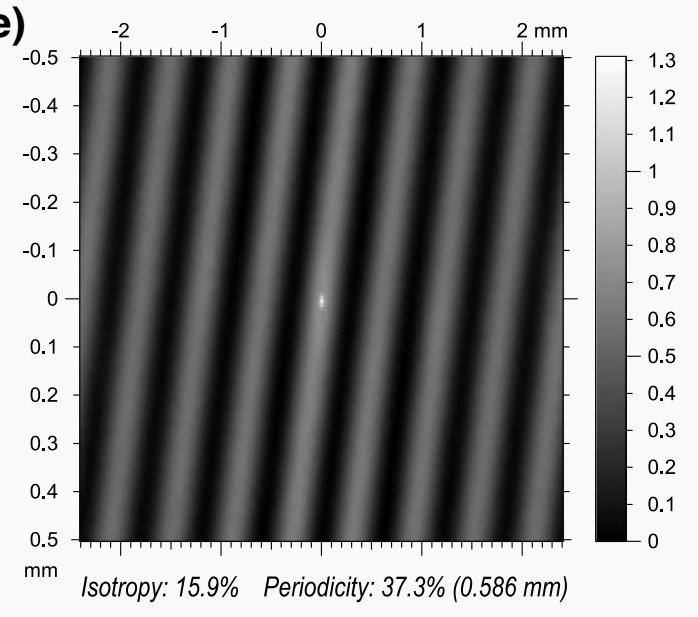

Process conditions: rotating speed $n=300 \mathrm{rpm}$, machining time $t=15$ minutes. Workpiece material: Copper-zinc-lead Alloy (CuZn39Pb2). Roughness parameters: with Gaussian filter $(0.8 \mathrm{~mm})$, Talysurf CLI 2000 and TalyMap software (Taylor Hobson Precision Ltd, England). 
perception of recognizing differences between signal patterns, the energy median in all the 12 classes could be analyzed at the same time, as presented in Fig. 13b. The chart depicts a clear growth in spectrum intensity along with a measurement sample shift from the machining area with low energy to one with higher energy. A change in the rotor's rotational speed proportionally influences the growth of spectrum intensity only in the case of locations with a high machining potential. This analysis also makes it possible to establish the spectrum intensity limiting value, the exceeding of which can be indicative of machining in a favorable part of an abrasive particle stream: in the case described, the limit level was established as the average value recorded on the chromagram, which was 0.3578

\subsection{Compare experimental and DEM method results}

Experimental investigations of local RMS values of the AE signal, measured in the axial cross section of the working medium, confirm the results of simulation analyses carried out with the use of the DEM method. Figure 14 presents the exemplary results of both research methods.

In both research methods considered, the location of regions with low, medium, and high RMS values (Fig. 14b) and the particle velocities (Fig. 14a) is comparable in relation to the geometry of the cross section of the working medium.

Both AE and DEM methods allow one to determine the location of regions with a large and low-energy potential of the working medium. In both cases, the regions with the highest values of the parameters considered are located in the lower part of the working medium.

On the basis of the analysis of Fig. 14 and selected measurement points on the maps of the distribution of RMS (AE) and velocity values (DEM), it can be estimated that there is a linear relationship between these parameters with a directional coefficient equal approx to $10^{5}$ (for the rotational speed of $450 \mathrm{rpm})$ :

$A E_{\mathrm{rms}[\mathrm{V}]} \cong 10^{5} v_{[\mathrm{m} / \mathrm{s}]}$.

This means that possessing information about the value of the RMS signal from a given region of the working medium, we are able to roughly estimate the average kinetic energy value of a group of abrasive particles occupying a given area.

The analysis above indicates that both methods have a similar exploratory quality of the machining potential of the working medium. The DEM method allows one to determine in detail the velocity and energy of the working medium, assuming specific parameters and machining conditions (the type, shape, and mass of abrasive particles, the size of the working chamber, rotational speeds). On the other hand, the AE signal measurement method, which is a method of diagnostics of a real object, can be applied in workshop conditions.

\subsection{Machining results}

It has been experimentally confirmed that surface finishing in a rotating container smoothing machine takes place at a higher intensity in the region of a high energy level, determined on the basis of energy measurement of the AE emission signal.

Comparing the effectiveness of machining within $15 \mathrm{~min}$ (defined for a rotational speed of $300 \mathrm{rpm}$ ), by evaluating the geometric structure of the workpiece surface, it can be seen that the surface is more smoothed in the case of a high kinetic energy region (Fig. 15).

This results in rapid removal of lay patterns formed by the pre-machining operation (single pre-machined mark is ticked with a dashed line in Fig. 15b). A significant reduction in the arithmetic mean deviation of surface roughness $(\mathrm{Sa}, 2.57$ to $1.7 \mu \mathrm{m})$ and the arithmetic mean deviation of the surface profile $(R a, 2.01$ to $1.39 \mu \mathrm{m})$ have been obtained (Fig. 15a, c). The form of the surface autocorrelation function also changes significantly, confirming the elimination of periodic components in the geometric structure of the surface and unification of surface structure. This results in an increase in isotropy (from 15.9 to $32.2 \%$ ) of the surface machined in high kinetic energy region (cf. Fig. 15d, e.

For this reason, it can be argued that an increase in the intensity of machining process carried out in the region of high kinetic energy contributes to an increase in the efficiency of machining in the considered constant time (15 min). However, it is important to realize that with an increase of the processing time, the high value of accumulated energy on a relatively small area can increase the roughness of the surface machined (i.e., by erosion craters). Therefore, in order to ensure a certain low surface roughness in this type of finishing process, by active process control, the working speed of the medium must be reduced or the workpiece must be re-positioned to a region with a lower energy level.

\section{Conclusions and summary}

The method of AE signal measurement has an advantage over other methods in that the signal can be recorded directly from the surface of the workpiece, and it is a passive method that does not affect the condition of the object monitored. In the current methods of working medium energy measurement, e.g., with the use of Almen strips or a force sensor, the measurements are carried out before the process (without the presence of the machining workpiece). Moreover, none of the energy measuring techniques were carried out in a direct way but estimated with the functional relation (Eq. 1) in relation to the abrasive medium velocity.

In the method proposed, the energy of the medium can be measured via $\mathrm{AE}$ directly from the workpiece surface (or its holder) or from a probe. This is an advantage over other 
methods used so far, as it is possible to determine the energy at precisely defined regions of the working medium. In addition, the $\mathrm{AE}$ sensor is a sensitive tool and it reacts to various types of elementary phenomena. Unlike the force sensor, it is also possible to measure low-energy and non-impact contacts.

The method based on an evaluation of the AE signal value is a convenient tool for process monitoring that can be used for adaptive process control in the future. However, this requires extended research analyses focused on both basic phenomena and the whole abrasive finishing process, e.g., with regard to the orientation of the workpiece in relation to the direction of the impact of abrasive pieces.

The research conducted positively verified previous stimulation results, and it proved that the energy of the working medium in a centrifugal disc finishing machining process is variable in its axial cross section. The values and distribution of this energy can be established by measuring the maximum values of the acoustic emission signal, as a result of which maps of energy in an axial cross section of the working medium can be developed. Knowledge of the location and size of areas with the greatest operating energy can form the basis for indicating them in order to conduct machining with the greatest efficiency possible and technological quality of the machined surface. In such cases, the spatial orientation of workpieces should be relevantly placed with handles that would execute a positioning motion in the radial and axial coordinates system of the centrifugal disc finishing machine. To this end, it is necessary to employ a workpiece positioning system mounted on the top of the stationary part of the EC6-WET machine housing.

The results may be summarized as follows:

1. The distribution of energy in the working medium, for a specified rotational speed, is spatially diversified. For this reason, the intensity of the abrasive particles' impact on the workpiece is variable, depending on the instantaneous location of the workpiece.

2. The working medium energy can be established on the basis of measuring the acoustic emission signal value. The root mean square value, sound pressure, and short-time energy of the acoustic emission signal are proportional to the rotational speed of the centrifugal disc finishing machine's rotor, which proves a correlation with the kinetic energy of the abrasive particles.

3. The values of selected acoustic emission signal descriptors, both in reference to time and frequency, have a high level of correlation in relation to the rotational speed of the centrifugal disc finishing machine's rotor. Those parameters can be therefore used to monitor and control the centrifugal disc finishing process in order to increase its effectiveness by selecting a relevant spatial location for the workpiece.
Even though the research on the working stream's interaction energy was conducted on one type of centrifugal disc finishing machine with a relatively low-capacity working chamber, it should be expected that similar phenomena occur in other, considerably bigger disc finishing machines. The authors suppose that the method presented refers not only to other types of centrifugal disc finishing machines but also to those of the vibratory and barrel varieties.

\section{Compliance with ethical standards}

Conflict of interest The authors declare that they have no conflicts of interest.

Research involving human participants and/or animals For this type of study, the statement is not applicable.

Informed consent For this type of study, the statement is not applicable.

Open Access This article is distributed under the terms of the Creative Commons Attribution 4.0 International License (http:// creativecommons.org/licenses/by/4.0/), which permits unrestricted use, distribution, and reproduction in any medium, provided you give appropriate credit to the original author(s) and the source, provide a link to the Creative Commons license, and indicate if changes were made.

\section{References}

1. Sutowski P, Plichta J, Kałduński P (2019) Determining kinetic energy distribution of the working medium in centrifugal disc finishing process - part 1: theoretical and numerical analysis with DEM method. Int J Adv Manuf Technol. https://doi.org/10.1007/ s00170-019-03872-2

2. Yang S, Li W (2018) Surface finishing theory and new technology. Springer Berlin Heidelberg, Berlin, Heidelberg

3. Almen JO (1944) Shot blasting test. US Patent 2,350,440, Google Patents. https://patents.google.com/patent/US2350440A/en. Accessed 10 January 2019

4. Ciampini D, Papini M, Spelt J (2007) Impact velocity measurement of media in a vibratory finisher. J Mater Process Technol 183:347357. https://doi.org/10.1016/j.jmatprotec.2006.10.024

5. Ciampini D, Papini M, Spelt J (2008) Characterization of vibratory finishing using the Almen system. Wear 264:671-678. https://doi. org/10.1016/j.wear.2007.06.002

6. Sutowski P, Sutowska M (2017) Kapłonek W (2017) The use of high-frequency acoustic emission analysis for in-process assessment of the surface quality of aluminium alloy 5251 in abrasive waterjet machining. Proc Inst Mech Eng B J Eng Manuf 232:25472565. https://doi.org/10.1177/0954405417703428

7. Sutowski P, Nadolny K, Kapłonek W (2012) Monitoring of cylindrical grinding processes by use of a non-contact AE system. Int $\mathrm{J}$ Precis Eng Manuf 13:1737-1743. https://doi.org/10.1007/s12541012-0228-7

8. Sutowski P, Święcik R (2017) The estimation of machining results and efficiency of the abrasive electro-discharge grinding process of Ti6Al4V titanium alloy using the high-frequency acoustic emission and force signals. Int J Adv Manuf Technol 94:1263-1282. https:// doi.org/10.1007/s00170-017-1011-9 
9. Sutowski P, Nadolny K (2016) The identification of abrasive grains in the decohesion process by acoustic emission signal patterns. Int $\mathrm{J}$ Precis Eng Manuf 87:437-450. https://doi.org/10.1007/s00170016-8504-9

10. Avalon ZMM (2018) Operating manual for polishing machine (centrifugal disc finishing machine) type EC6. Department of Mechanics of Machines 'AVALON', Poland (in Polish)

11. Avalon ZMM (2018) Disc finishing machines. EC series (tabletop). http://www.en.avalon-machines.pl/files/site-en/download/ 2351/disc-finishing-machines.pdf. Accessed 15 May 2018

12. Kistler Instrument Corporation (2007) Acoustic emission sensor, type 8152 B. http://www.helmar.com.pl/helmar/plik/8152b111 nn3999.pdf. Accessed 02 Sept 2012

13. Kistler Instrument Corporation (2007) Acoustic emission Piezotron coupler, type 5125B. http://www.helmar.com.pl/helmar/ plik/5125b1_nn761.pdf. Accessed 02 Sept 2012

14. BS EN 1652:1998 Copper and copper alloys. Plate, sheet, strip and circles for general purposes
15. Copper Development Association (2004) Copper and copper alloys compositions, applications and properties. http://copperalliance. org.uk/resource-library/pub-120\%2D\%2D-copper-and-copperalloys. Accessed 20 May 2017

16. Leach WM (1994) Controlled-source analogous circuits and SPICE models for piezoelectric transducers. IEEE Trans Ultrason Ferroelectr Freq Control 41:60-66. https://doi.org/10.1109/58. 265821

17. Nazarchuk Z, Skalskyi V, Serhiyenko O (2017) Acoustic emission. Methodology and application. Springer International Publishing, Cham. https://doi.org/10.1007/978-3-319-49350-3

Publisher's note Springer Nature remains neutral with regard to jurisdictional claims in published maps and institutional affiliations. 